\title{
Increased Surgical Complications but Improved Overall Survival with Adult Living Donor Compared to Deceased Donor Liver Transplantation: A Systematic Review and Meta-Analysis
}

\author{
Wei Tang $\mathbb{D}^{\text {, Jian-Guo }}$ Qiu $\left(\mathbb{D}\right.$, Yang Cai $\mathbb{D}^{D}$, Luo Cheng $\mathbb{D}^{D}$, and Cheng-You Du \\ Department of Hepatobiliary Surgery, The First Affiliated Hospital of Chongqing Medical University, Chongqing 400016, China \\ Correspondence should be addressed to Cheng-You Du; duchengyou@126.com
}

Received 9 April 2020; Revised 19 July 2020; Accepted 7 August 2020; Published 25 August 2020

Academic Editor: Raffaele Serra

Copyright (c) 2020 Wei Tang et al. This is an open access article distributed under the Creative Commons Attribution License, which permits unrestricted use, distribution, and reproduction in any medium, provided the original work is properly cited.

\begin{abstract}
Background. Living donor liver transplantation (LDLT) provides an alternative to deceased donor liver transplantation (DDLT) for patients with end-stage liver disease in the circumstance of scarcity of deceased grafts. However, the outcomes of LDLT remain controversial. Method. A systematic review and meta-analysis were performed to compare the outcomes of LDLT with DDLT. Twelve outcomes were assessed. Results. Thirty-nine studies involving 38563 patients were included. LDLT was comparable in red blood cell transfusion, perioperative mortality, length of hospital stay, retransplantation rate, hepatitis $\mathrm{C}$ virus recurrence rate, and hepatocellular carcinoma recurrence rate with DDLT. Cold ischemia time was shorter and duration of recipient operation was longer in LDLT. Postoperative intra-abdominal bleeding rate occurred less frequently in LDLT recipients (odds ratio $(\mathrm{OR})=0.64,95$ \%confidence interval $(\mathrm{CI})=0.46-0.88, P=0.006)$, but this did not decrease the perioperative mortality. LDLT was associated with significantly higher biliary $(\mathrm{OR}=2.23,95 \% \mathrm{CI}=1.59-3.13, P<0.00001)$ and vascular $(\mathrm{OR}=2.00,95 \% \mathrm{CI}=1.31-3.07, P=0.001)$ complication rates and better overall survival $(\mathrm{OS})(1$ year: $\mathrm{OR}=1.32,95 \% \mathrm{CI}=1.01-1.72, P=0.04 ; 3$ years: $\mathrm{OR}=1.39,95 \%$ $\mathrm{CI}=1.14-1.69, P=0.0010$; and 5 years: $\mathrm{OR}=1.33,95 \% \mathrm{CI}=1.04-1.70, P=0.02)$. According to subgroup analysis, biliary complication rate and OS improved dramatically as experience increased, while vascular complication rate could not be improved because it was mainly caused by the difference of the donor type itself. Conclusions. LDLT remains a valuable option for patients in need of liver transplantation for it provides an excellent alternative to DDLT without compromising recipient outcomes. Further refinement in biliary and vascular reconstruction techniques and the accumulation of liver transplantation centers' experience are the key factors in expanding the application of LDLT.
\end{abstract}

\section{Introduction}

Liver transplantation (LT) is a well-established therapeutic option for patients with irremediable end-stage liver disease. However, the worldwide scarcity of deceased donor livers is the greatest challenge nowadays. Nearly a quarter of patients with liver failure died while waiting for liver grafts [1-4]. Fortunately, in 1966, the idea of living donor liver transplantation (LDLT) was aroused [5], and in 1989, the first successful LDLT was performed [6]. After decades of development, LDLT has been widely considered as an alternative to deceased donor liver transplantation (DDLT). Compared with DDLT, it is generally accepted by us that LDLT has shorter waiting time, younger donor age, and better organization of surgery time. Oppositely, LDLT is criticized for its smaller graft volume, donor risk, and ethical controversies. The efficacy of LDLT versus DDLT is controversial. Although lots of studies comparing the clinical outcomes of LDLT with DDLT were carried out in the past decades, the issues remained for the inconformity of conclusions. Whether a distinct disparity exists between these 2 therapeutic regimens and which type of LT can obtain better clinical outcomes need further investigation. Therefore, with the aim of comparing the outcomes of LDLT with DDLT, we systematically summarized the current available data and performed a meta-analysis. 


\section{Materials and Methods}

2.1. Literature Search and Study Selection. We adhered to the 2009 preferred reporting items for systematic reviews and meta-analysis statement. To provide an adequate overview of the current literature, databases of PubMed, Embase, and the Cochrane Library from inception to 21 November 2019 were chosen for screening; an additional search with Google Scholar was performed to supplement the primary search. A combination of the following terms was used as a strategy of literature search: living donor, deceased donor, cadaveric donor, CLT (cadaveric liver transplantation), LDLT, DDLT, and liver transplantation. Two authors (Tang and Qiu) carried out the search independently and any discrepancies regarding the study selection were resolved by them. No restriction of language or publication type was set in the search. The study protocol was approved by the Science and Research Office of the First Affiliated Hospital of Chongqing Medical University.

2.2. Inclusion and Exclusion Criteria. The inclusion criteria were (1) published prospective or retrospective cohort studies and randomized controlled trials, (2) studies comparing LDLT with DDLT in adult patients, and (3) studies with at least 1 of the aforementioned outcomes. The exclusion criteria were (1) case reports, reviews, letters, editorials, and conference reports; (2) studies lacking a control group; (3) studies without available data; (4) studies investigating emergency LT; (5) studies without a clear description of methods or baseline characteristics; and (6) studies with less than 100 recipients in total. Moreover, for studies from the same database, only the one with the largest sample size was included.

2.3. Outcomes of Interest. We assessed 12 outcomes of LT in this meta-analysis, including cold ischemia time (CIT), amount of allogeneic red blood cell (RBC) transfusion, duration of the recipient operation (DRO), postoperative intraabdominal bleeding rate, perioperative mortality, length of hospital stay, vascular complication rate, biliary complication rate, retransplantation rate, hepatitis $\mathrm{C}$ virus $(\mathrm{HCV})$ recurrence rate, hepatocellular carcinoma (HCC) recurrence rate, and patient overall survival (OS).

2.4. Quality Assessment and Data Extraction. The methodological quality of each included study was assessed using the Newcastle-Ottawa quality assessment scale [7] by 2 reviewers (Cai and Cheng) independently. The extracted data included general information (first author, year of publication, source journal, country, study design, sample size, diagnoses of patients, recipient and donor age, follow-up period, gender, and the source of clinical data) and 12 outcomes (CIT, RBC transfusion, DRO, postoperative intra-abdominal bleeding rate, perioperative mortality, length of hospital stay, vascular complication rate, biliary complication rate, retransplantation rate, $\mathrm{HCV}$ recurrence rate, $\mathrm{HCC}$ recurrence rate, and OS). The obtained data were then compared by the reviewers, inconsistencies were discussed, and a third reviewer (Du) was consulted to reach a consensus if necessary.
2.5. Statistical Analysis. The meta-analysis was carried out in accordance with the Cochrane Reviewer's Handbook, and statistical analyses were performed with the Review Manager (RevMan) software (Version 5.3, The Cochrane Collaboration, The Nordic Cochrane Center, Copenhagen, Denmark). The results were presented by odds ratio (OR) with $95 \%$ confidence interval (CI) for dichotomous data and mean difference (MD) with 95\% CI for continuous data. For data which were reported as medians and ranges, the methods described by Hozo et al. [8] and Higgins and Green [9] were used to transform into mean and standard deviation. Heterogeneity among studies was estimated using the $\mathrm{Chi}^{2}$-square test $(P<0.10$ represented statistically significant heterogeneity) and the $I^{2}$ test $\left(I^{2}>50 \%\right.$ represented statistically significant heterogeneity). When indicating no significant heterogeneity, a fixed-effect model was used. Otherwise, a random-effect model was used and a subgroup analysis was performed to explore the discrepancy. Funnel plots were performed to assess the publication bias, and the bias was excluded if a symmetrical distribution was shown. Moreover, a sensitivity analysis was performed by removing each study in turn to evaluate the stability of a pooled estimate. Pooled analyses were visualized with forest plots, and statistical significance was considered at $P<0.05$.

\section{Results}

3.1. Study Characteristics and Quality Assessment. As shown in a flow diagram (Figure 1), 1439 articles were found using a combination of search terms and 1390 irrelevant articles were excluded according to the inclusion and exclusion criteria after screening titles and abstracts. Then, 10 studies were excluded after full text review for the following reasons: 2 studies were based on overlapping data from the same database, 5 studies lacked a control group, 1 study had no available data, 1 study focused on pediatric LT, and 1 study was about combined liver and kidney transplantation. Finally, 39 studies [4, 10-47] (7 prospective cohorts and 32 retrospective cohorts) were included in the meta-analysis.

The characteristics of the 39 included studies are presented in Table 1. All studies were well designed to compare two arms: LDLT and DDLT. The follow-up period ranged from 1988 to 2019. Fifteen studies investigated patients with various liver diseases, 10 studies were about hepatitis $\mathrm{B} / \mathrm{C}$ virus-related diseases, and 14 studies focused on HCC. Three studies [21, 37, 40] were derived from the Adult-to-Adult Living Donor Liver Transplantation Cohort Study, 3 studies $[20,39,46]$ were based on the United Network for Organ Sharing, 1 study [18] was derived from the University Health System Consortium and Scientific Registry of Transplant Recipients, 1 study [14] was based on the China Liver Transplant Registry, and the rest of the studies were derived from a single center or from multiple institutions. These studies were conducted in the east $(n=14)$ and in the west $(n=25)$. Most of the included studies showed satisfactory quality with selection criteria, comparability of patient characteristics, and adequate follow-up. All cohorts got 6 or more stars (Table 2). 


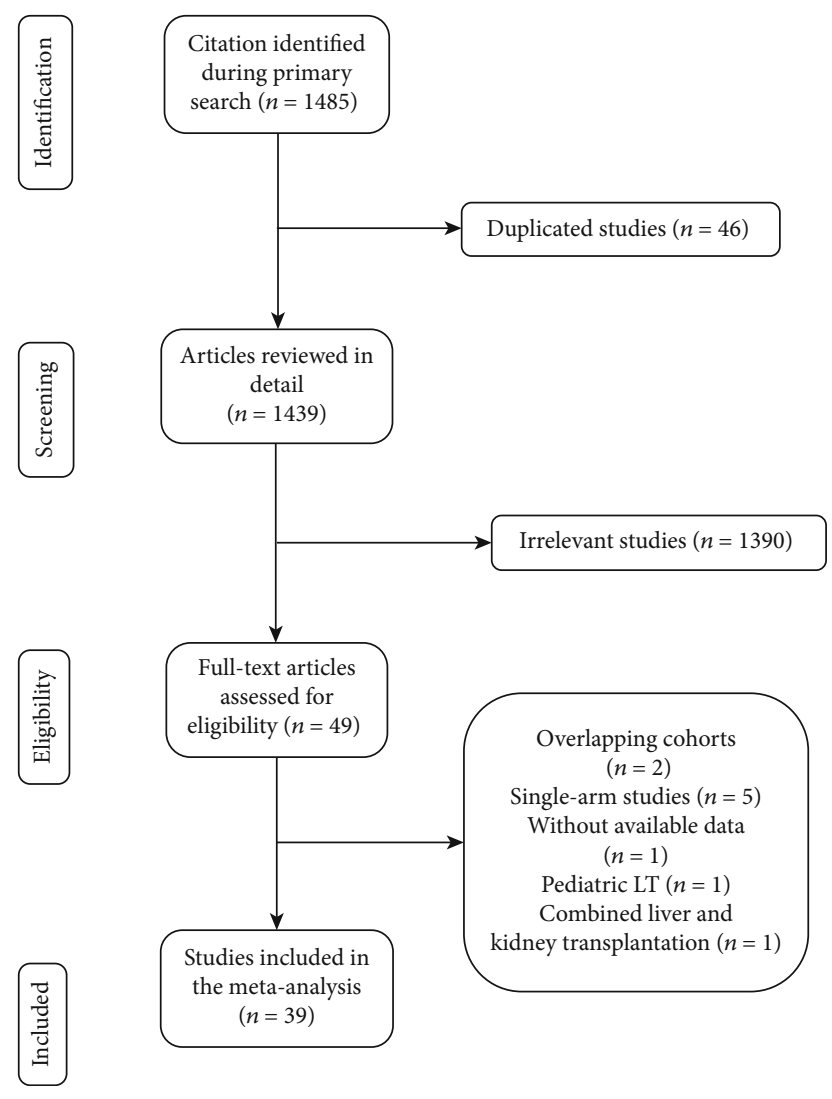

FIGURE 1: Flow diagram showing process of literature search and study selection.

3.2. CIT. Six studies $[11,16,20,31,32,40]$ reported CIT, and all six of them suggested it was shorter in LDLT. There was significant heterogeneity $\left(P<0.00001, I^{2}=96 \%\right)$. A randomeffect model indicated a significant difference between LDLT and DDLT, and CIT of LDLT was much shorter than DDLT $(\mathrm{WMD}=-373.39,95 \% \mathrm{CI}=-399.41$ to $-347.37, P<0.00001$; Figure 2).

3.3. RBC Transfusion. Four studies [32, 38, 43, 45] reported $\mathrm{RBC}$ transfusion, with all four of them indicating no significant difference between LDLT and DDLT. No significant heterogeneity was observed $\left(P=0.71, I^{2}=0 \%\right)$. A fixed-effect model was used, and pooled results showed that LDLT was comparable with DDLT in RBC transfusion $(\mathrm{WMD}=0.69,95 \% \mathrm{CI}=-0.14$ to $1.51, P=0.10$; Figure 3 ).

3.4. DRO. DRO was reported in four studies [14, 34, 40, 45], and all four of them showed that it was significantly longer in LDLT. No significant heterogeneity was observed $(P=0.13$, $\left.I^{2}=47 \%\right)$. A fixed-model was used, and the pooled DRO of LDLT was found to be significantly longer than that of DDLT $(\mathrm{WMD}=141.68,95 \% \mathrm{CI}=129.19$ to $154.16, P<0.00001$; Figure 4).

3.5. Postoperative Intra-Abdominal Bleeding Rate. Six studies $[12-14,31,34,40]$ reported the postoperative intraabdominal bleeding rate. While five of them $[12,14,31,34$, 40] indicated no significant difference between LDLT and
DDLT, 1 study [14] showed a significantly lower intraabdominal bleeding rate in LDLT. Notably, pooled results with a fixed-effect model revealed that the intra-abdominal bleeding rate of LDLT was significantly lower than that of DDLT $(\mathrm{OR}=0.64,95 \% \mathrm{CI}=0.46$ to $0.88, P=0.006$; Figure 5). Moreover, no significant heterogeneity was observed $\left(P=0.37, I^{2}=8 \%\right)$.

3.6. Perioperative Mortality. Ten studies [18, 25-27, 32, 36, $38,40-42]$ reported perioperative mortality, and all of them suggested no significant difference between LDLT and DDLT. No significant heterogeneity was observed $(P=0.10$, $\left.I^{2}=39 \%\right)$. A fixed-effect model suggested comparable perioperative mortality between LDLT and DDLT $(\mathrm{OR}=1.03$, $95 \% \mathrm{CI}=0.81$ to $1.29, P=0.82$; Figure 6 ).

3.7. Length of Hospital Stay. Four studies [14, 31, 35, 45] reported the length of hospital stay, and all of them showed that no significant difference existed between LDLT and DDLT. A fixed-effect model revealed a similar length of hospital stay between LDLT and DDLT (WMD $=1.82,95 \% \mathrm{CI}$ $=-0.91$ to $4.56, P=0.19$; Figure 7$)$. There was no significant heterogeneity observed $\left(P=0.61, I^{2}=0 \%\right)$.

3.8. Vascular Complication Rate. Six studies [31, 34, 38, 40, $42,45]$ reported the vascular complication rate. While five of them [31, 34, 38, 42, 45] suggested no significant difference between LDLT and DDLT, 1 study [40] showed a significantly higher vascular complication rate in LDLT. There was no significant heterogeneity $\left(P=0.11, I^{2}=45 \%\right)$. A fixed-effect model showed a significantly higher vascular complication rate in LDLT $(\mathrm{OR}=2.00,95 \% \mathrm{CI}=1.31$ to $3.07, P=0.001$; Figure 8).

3.9. Biliary Complication Rate. Fourteen studies $[10,11,13$, $14,17,19,23,31,34,36,38,40,42,45]$ reported the biliary complication rate. Four studies $[10,13,17,38]$ showed no significant difference between LDLT and DDLT, while the rest of the studies [11, 14, 19, 23, 31, 34, 36, 40, 42, 45] indicated a significantly higher biliary complication rate in LDLT. Significant heterogeneity existed $(P<0.00001$, $\left.I^{2}=77 \%\right)$. A random-effect model revealed a significantly higher biliary complication rate in LDLT $(\mathrm{OR}=2.23,95 \%$ $\mathrm{CI}=1.59$ to $3.13, P<0.00001$; Figure 9).

3.10. Retransplantation Rate. Eight studies [11, 15, 22, 24, 27, $31,32,42]$ reported the retransplantation rate. While six of them $[15,22,24,27,31,32]$ indicated no significant difference between LDLT and DDLT, 2 studies [11, 42] showed a significantly higher retransplantation rate in LDLT. No significant heterogeneity was observed $\left(P=0.20, I^{2}=29 \%\right)$. A fixed-effect model showed a comparable retransplantation rate between LDLT and DDLT $(\mathrm{OR}=1.29,95 \% \mathrm{CI}=0.87$ to $1.93, P=0.21$; Figure 10).

3.11. HCV Recurrence Rate. Four studies [11, 23, 24, 46] reported the HCV recurrence rate. Two of them $[24,46]$ suggested no significant difference between LDLT and DDLT, 1 [23] showed a significantly higher HCV recurrence rate in LDLT, and 1 [11] showed a lower HCV recurrence rate in 


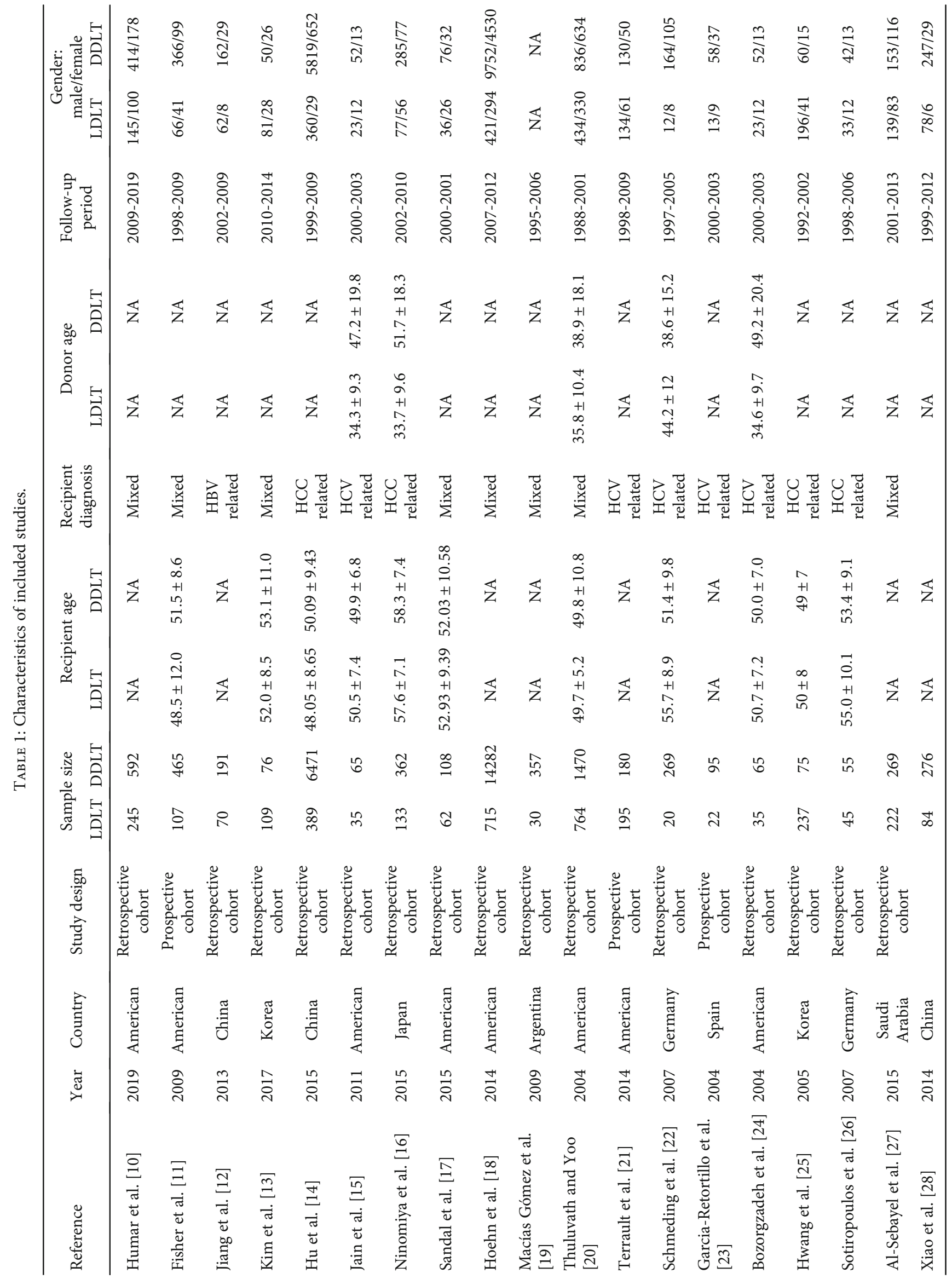




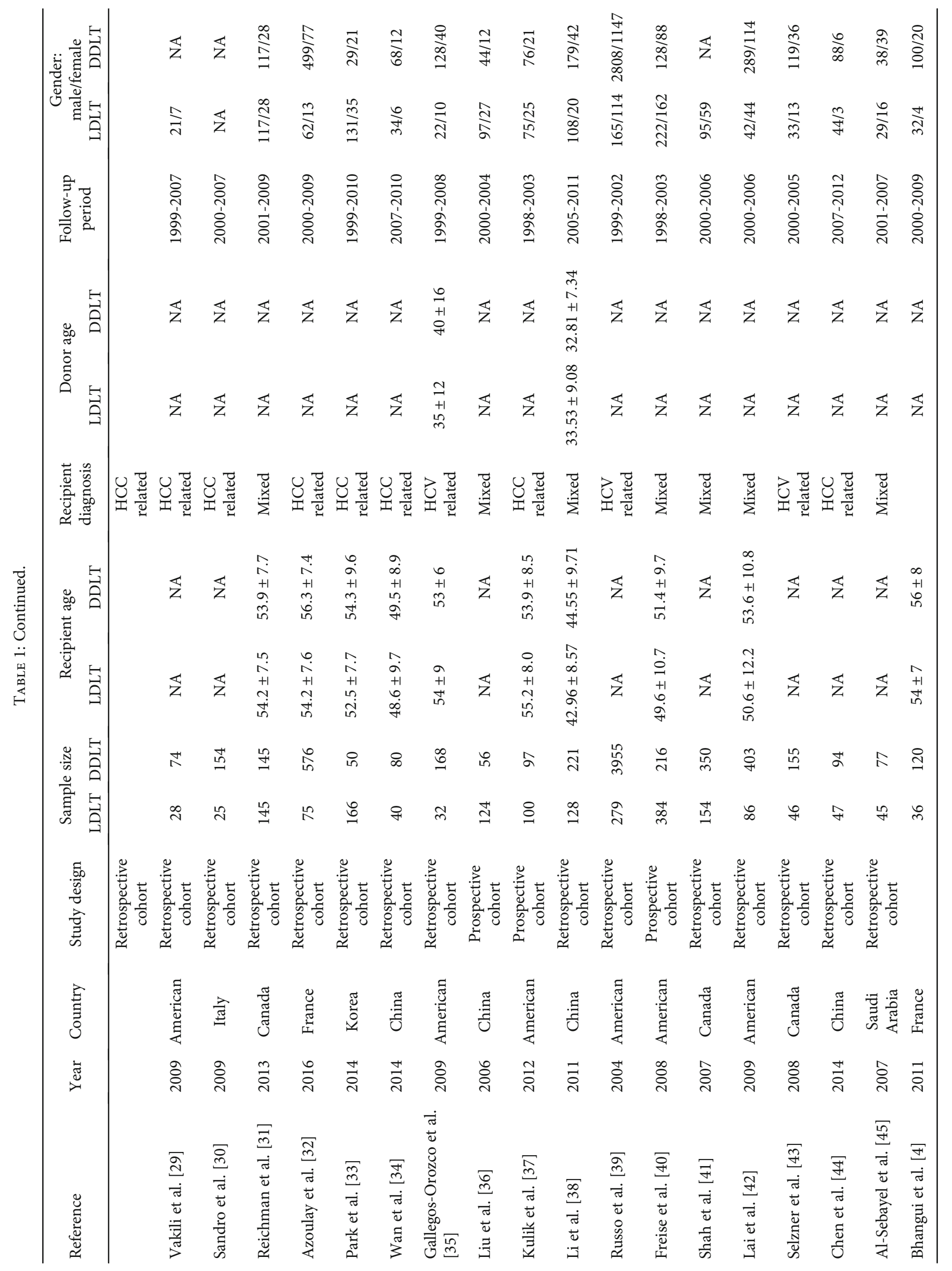




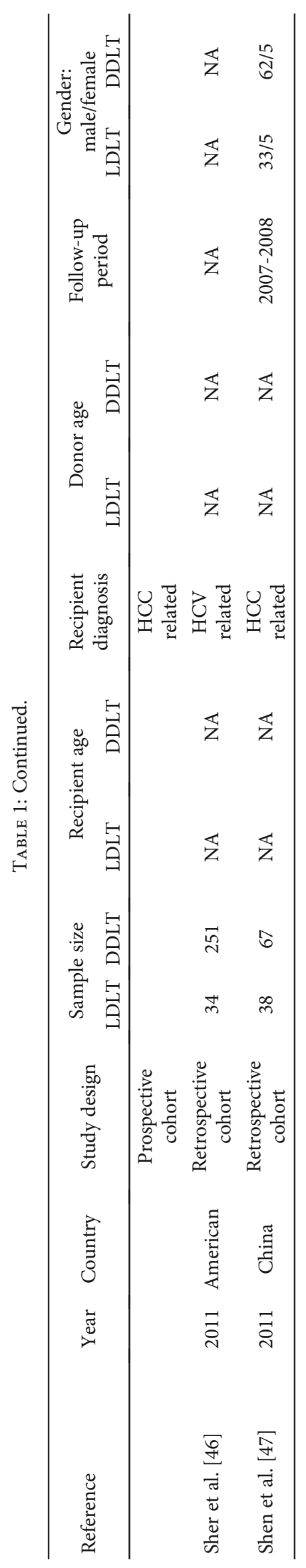


TABLe 2: Newcastle-Ottawa quality assessment scale for cohort studies.

\begin{tabular}{|c|c|c|c|c|}
\hline Reference & Selection & Comparability & Outcome & Total \\
\hline Humar et al. [10] & 4 & 2 & 3 & 9 \\
\hline Fisher et al. [11] & 4 & 1 & 3 & 8 \\
\hline Jiang et al. [12] & 3 & 2 & 3 & 8 \\
\hline Kim et al. [13] & 4 & 1 & 2 & 7 \\
\hline Hu et al. [14] & 4 & 1 & 2 & 7 \\
\hline Jain et al. [15] & 3 & 2 & 3 & 8 \\
\hline Ninomiya et al. [16] & 4 & 1 & 3 & 8 \\
\hline Sandal et al. [17] & 4 & 1 & 2 & 7 \\
\hline Hoehn et al. [18] & 4 & 2 & 3 & 9 \\
\hline Macías Gómez et al. [19] & 3 & 0 & 3 & 6 \\
\hline Thuluvath and Yoo [20] & 4 & 1 & 3 & 8 \\
\hline Terrault et al. [21] & 4 & 2 & 3 & 9 \\
\hline Schmeding et al. [22] & 3 & 2 & 3 & 8 \\
\hline Garcia-Retortillo et al. [23] & 4 & 2 & 3 & 9 \\
\hline Bozorgzadeh et al. [24] & 3 & 1 & 3 & 7 \\
\hline Hwang et al. [25] & 4 & 2 & 3 & 9 \\
\hline Sotiropoulos et al. [26] & 4 & 2 & 3 & 9 \\
\hline Al-Sebayel et al. [27] & 3 & 1 & 3 & 7 \\
\hline Xiao et al. [28] & 4 & 1 & 2 & 7 \\
\hline Vakili et al. [29] & 4 & 0 & 3 & 7 \\
\hline Sandro et al. [30] & 4 & 2 & 3 & 9 \\
\hline Reichman et al. [31] & 3 & 2 & 3 & 8 \\
\hline Azoulay et al. [32] & 4 & 2 & 3 & 9 \\
\hline Park et al. [33] & 4 & 2 & 3 & 9 \\
\hline Wan et al. [34] & 4 & 2 & 3 & 9 \\
\hline Gallegos-Orozco et al. [35] & 3 & 2 & 3 & 8 \\
\hline Liu et al. [36] & 4 & 2 & 3 & 9 \\
\hline Kulik et al. [37] & 4 & 1 & 3 & 8 \\
\hline Li et al. [38] & 3 & 2 & 3 & 8 \\
\hline Russo et al. [39] & 4 & 2 & 2 & 8 \\
\hline Freise et al. [40] & 3 & 2 & 3 & 8 \\
\hline Shah et al. [41] & 3 & 2 & 3 & 8 \\
\hline Lai et al. [42] & 3 & 1 & 3 & 7 \\
\hline Selzner et al. [43] & 3 & 2 & 3 & 8 \\
\hline Chen et al. [44] & 4 & 1 & 2 & 7 \\
\hline Al-Sebayel et al. [45] & 3 & 2 & 3 & 8 \\
\hline Bhangui et al. [4] & 4 & 2 & 3 & 9 \\
\hline Sher et al. [46] & 3 & 1 & 3 & 7 \\
\hline Shen et al. [47] & 4 & 1 & 2 & 7 \\
\hline
\end{tabular}

LDLT. Significant heterogeneity was observed $(P=0.001$, $\left.I^{2}=81 \%\right)$. A random-effect model suggested no significant difference between LDLT and DDLT $(\mathrm{OR}=1.10,95 \% \mathrm{CI}=$ 0.39 to $3.10, P=0.86$; Figure 11 ).

3.12. HCC Recurrence Rate. Eight studies [14, 16, 25, 26, 28, $33,37,44]$ reported the 1 -year HCC recurrence rate; while six of them $[16,25,26,33,37,44]$ showed no significant difference between LDLT and DDLT, 2 [14, 28] suggested a significantly lower recurrence rate in LDLT. Five studies
$[14,16,26,28,37]$ reported the 3-year HCC recurrence rate; three of them $[16,26,28]$ indicated no significant difference between LDLT and DDLT, 1 [14] showed a significantly lower recurrence rate in LDLT, and 1 [37] suggested a higher recurrence rate in LDLT. Eight studies [14, 16, 26, 28, 32, 33, $37,44]$ reported the 5 -year HCC recurrence rate; 5 of them $[16,26,28,32,44]$ indicated no significant difference between LDLT and DDLT, 2 [33, 37] showed a significantly higher recurrence rate in LDLT, and 1 [14] suggested a lower recurrence rate in LDLT. Significant heterogeneity was 


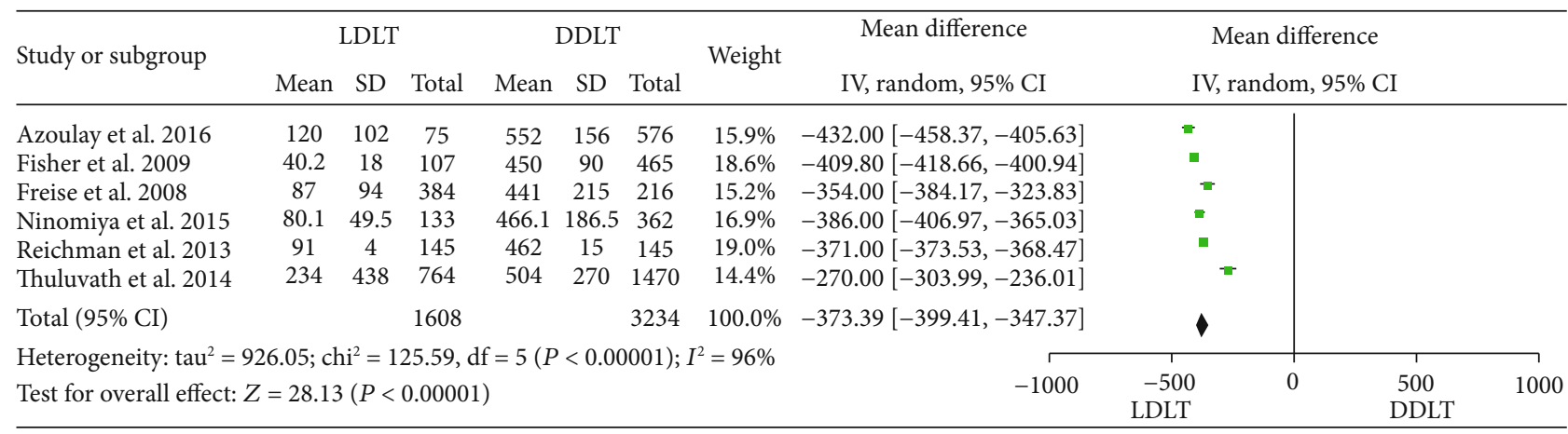

FIGURE 2: Meta-analysis of studies comparing CIT between LDLT and DDLT recipients based on a random-effect model. CIT: cold ischemia time; LDLT: living donor liver transplantation; DDLT: deceased donor liver transplantation.

\begin{tabular}{|c|c|c|c|c|c|c|c|c|c|c|c|}
\hline \multirow{2}{*}{ Study or subgroup } & \multicolumn{3}{|c|}{ LDLT } & \multicolumn{3}{|c|}{ DDLT } & \multirow{2}{*}{ Weight } & \multicolumn{2}{|l|}{ Mean difference } & \multicolumn{2}{|l|}{ Mean difference } \\
\hline & Mean & $\mathrm{SD}$ & Total & Mean & $\mathrm{SD}$ & Total & & IV, fixed, 95\% CI & \multicolumn{3}{|c|}{ IV, fixed, 95\% CI } \\
\hline Al-Sebayel et al. 2007 & 4 & 16.3 & 45 & 6 & 6.7 & 77 & $2.7 \%$ & $-2.00[-6.99,2.99]$ & \multirow{2}{*}{\multicolumn{3}{|c|}{ 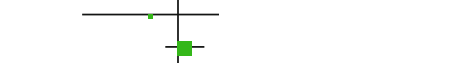 }} \\
\hline Azoulay et al. 2016 & 4.8 & 5.9 & 75 & 4.3 & 6.1 & 576 & $33.5 \%$ & $0.50[-0.93,1.93]$ & & & \\
\hline Li et al. 2011 & 4.7 & 5.38 & 128 & 3.84 & 6.35 & 221 & $43.4 \%$ & $0.86[-0.39,2.11]$ & \multicolumn{3}{|c|}{-} \\
\hline Selzner et al. 2008 & 5 & 6 & 46 & 4 & 3.7 & 155 & $20.4 \%$ & $1.00[-0.83,2.83]$ & \\
\hline Total $(95 \%$ CI $)$ & & & 294 & & & 1029 & $100.0 \%$ & $0.69[-0.14,1.51]$ & & $\checkmark$ & \\
\hline \multicolumn{8}{|c|}{ Heterogeneity: $\mathrm{chi}^{2}=1.36 ; \mathrm{df}=3(P=0.71) ; I^{2}=0 \%$} & -20 & -10 & 10 & 20 \\
\hline \multicolumn{8}{|c|}{ Test for overall effect: $Z=1.64(P=0.10)$} & & LDLT & DDLT & \\
\hline
\end{tabular}

FIGURE 3: Meta-analysis of studies comparing RBC transfusion between LDLT and DDLT recipients based on a fixed-effect model. RBC: red blood cell; LDLT: living donor liver transplantation; DDLT: deceased donor liver transplantation.

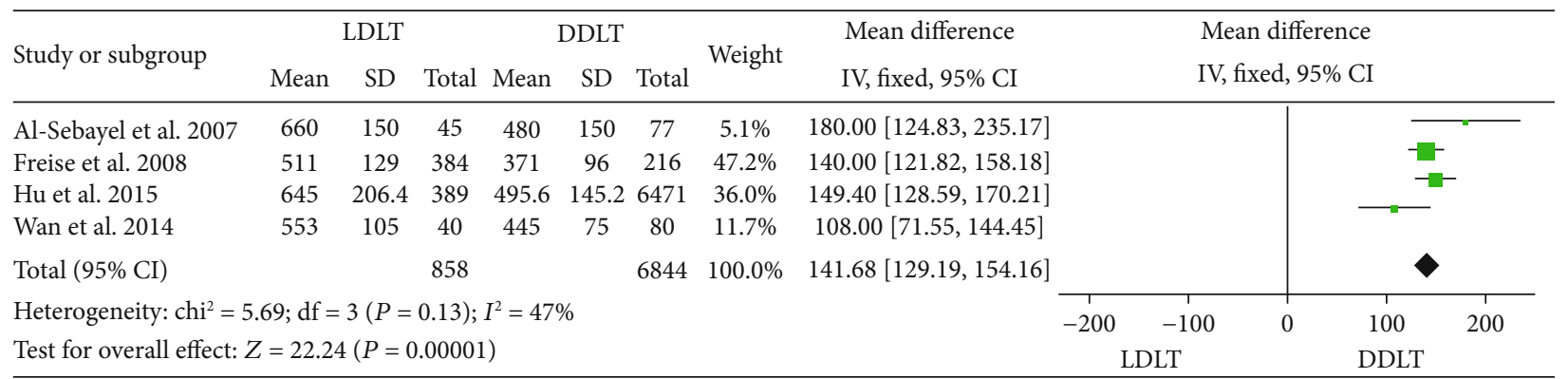

FIGURE 4: Meta-analysis of studies comparing DRO between LDLT and DDLT recipients based on a fixed-effect model. DRO: duration of the recipient operation; LDLT: living donor liver transplantation; DDLT: deceased donor liver transplantation.

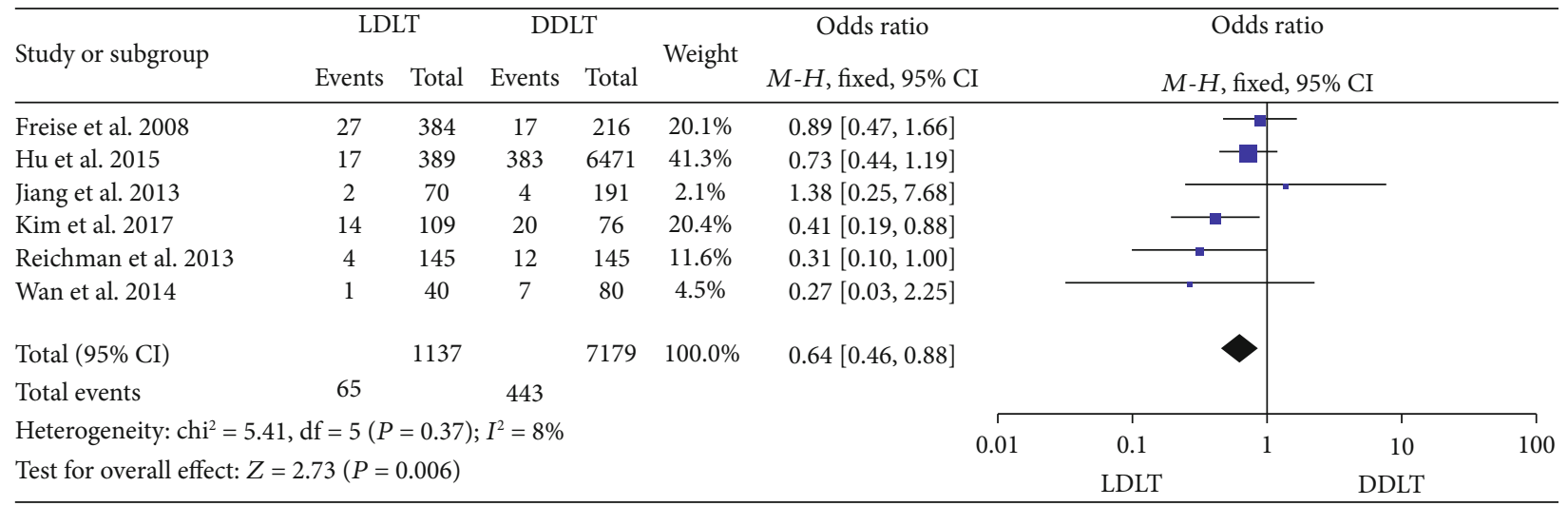

FIGURE 5: Meta-analysis of studies comparing postoperative intra-abdominal bleeding rate between LDLT and DDLT recipients based on a fixed-effect model. LDLT: living donor liver transplantation; DDLT: deceased donor liver transplantation. 


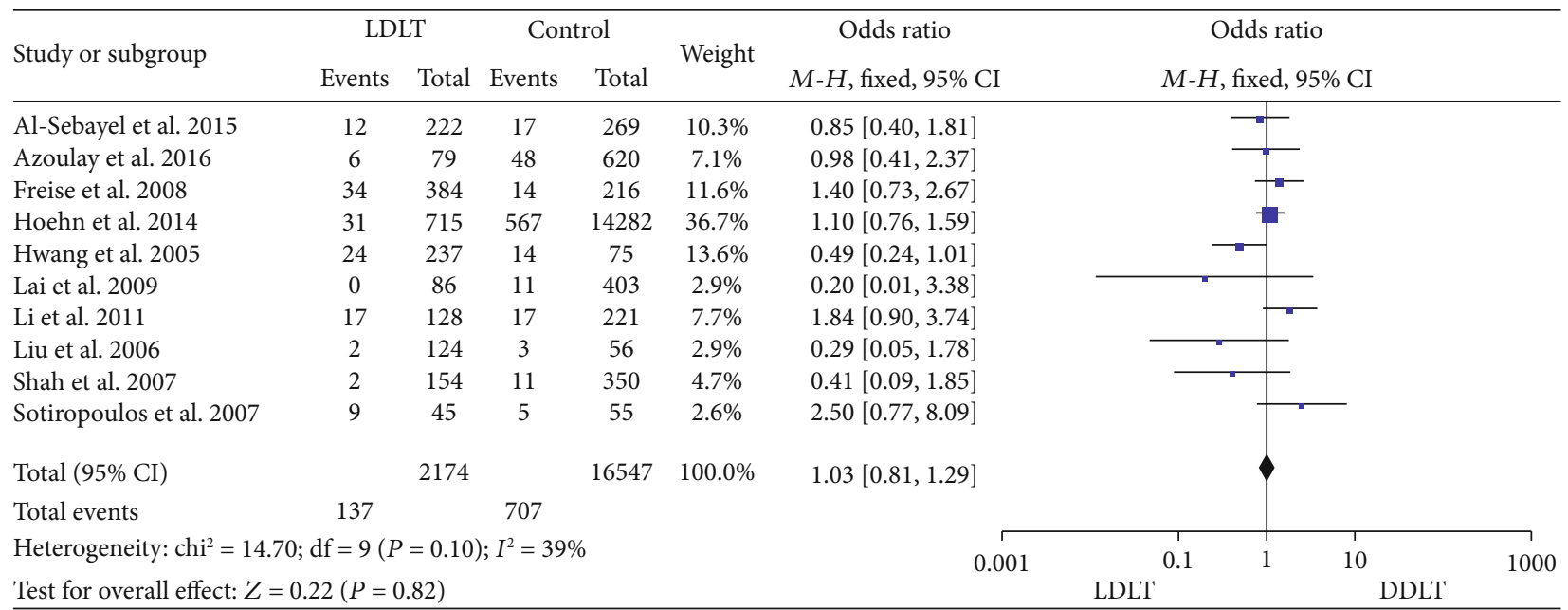

FIGURE 6: Meta-analysis of studies comparing perioperative mortality between LDLT and DDLT recipients based on a fixed-effect model. LDLT: living donor liver transplantation; DDLT: deceased donor liver transplantation.

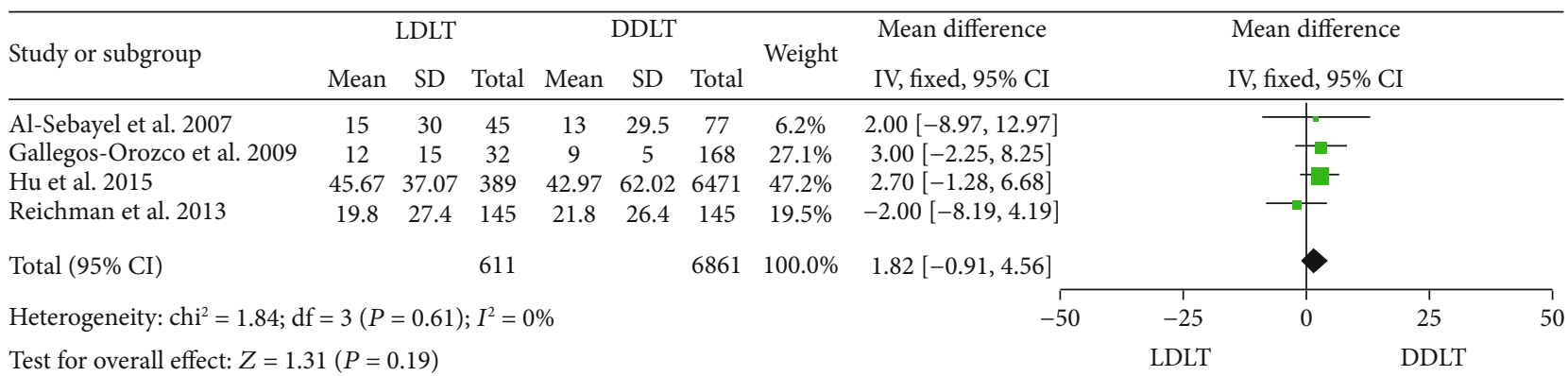

FIGURE 7: Meta-analysis of studies comparing length of hospital stay between LDLT and DDLT recipients based on a fixed-effect model. LDLT: living donor liver transplantation; DDLT: deceased donor liver transplantation.

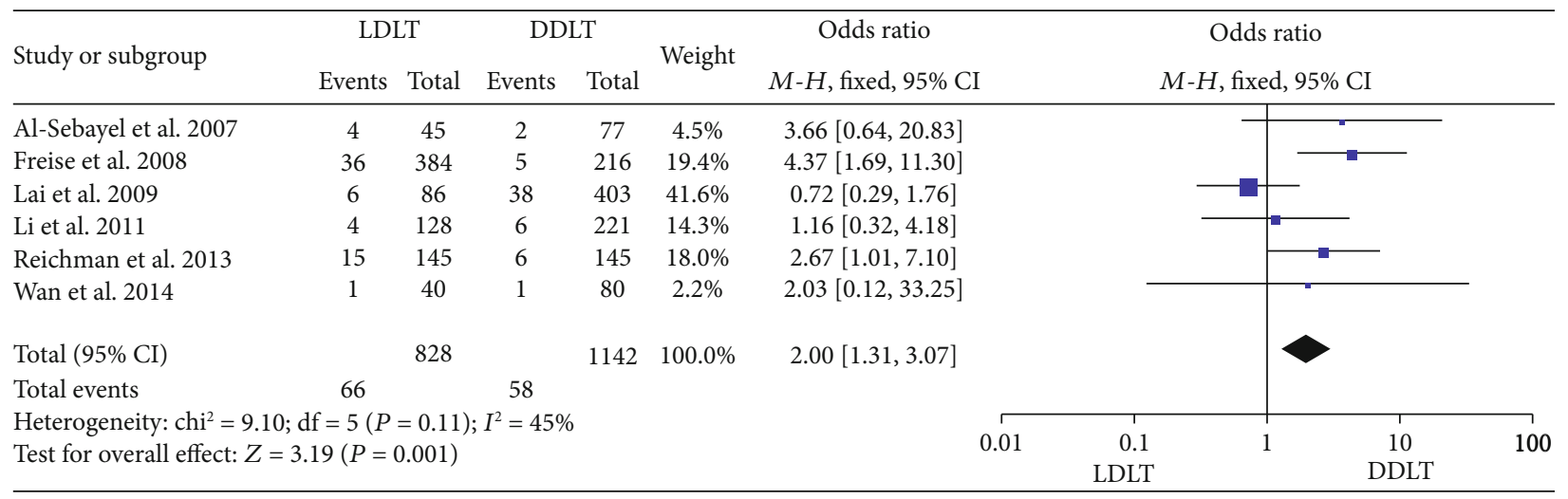

FIGURE 8: Meta-analysis of studies comparing the vascular complication rate between LDLT and DDLT recipients based on a fixed-effect model. LDLT: living donor liver transplantation; DDLT: deceased donor liver transplantation.

observed ( 1 year: $P=0.0007, I^{2}=72 \% ; 3$ years: $P=0.001$, $I^{2}=78 \%$; and 5 years: $\left.P<0.00001, I^{2}=81 \%\right)$. Randomeffect models indicated comparable 1-, 3-, and 5-year HCC recurrence rates between LDLT and DDLT (1 year: $\mathrm{OR}=1.00,95 \% \mathrm{CI}=0.61$ to $1.66, P=0.99$, see Figure 12 ; 3 years: $\mathrm{OR}=0.86,95 \% \mathrm{CI}=0.52$ to $1.41, P=0.54$, see Figure 13 ; and 5 years: $\mathrm{OR}=0.87,95 \% \mathrm{CI}=0.54$ to 1.38 , $P=0.55$, see Figure 14).
3.13. OS. Eighteen studies $[4,11,13-16,21,24-28,34,35,39$, $41,44,47]$ reported 1-year OS. Four of them [13, 14, 16, 28] suggested a significantly higher 1 -year OS in LDLT, and the rest $[4,11,15,21,24-27,34,35,39,41,44,47]$ showed no significant difference between LDLT and DDLT. A randomeffect model revealed a significantly higher 1-year OS in LDLT $\quad(\mathrm{OR}=1.32, \quad 95 \% \mathrm{CI}=1.01$ to $1.72, \quad P=0.04$; Figure 15). Fifteen studies $[4,10,11,14-16,21,25-30,35$, 


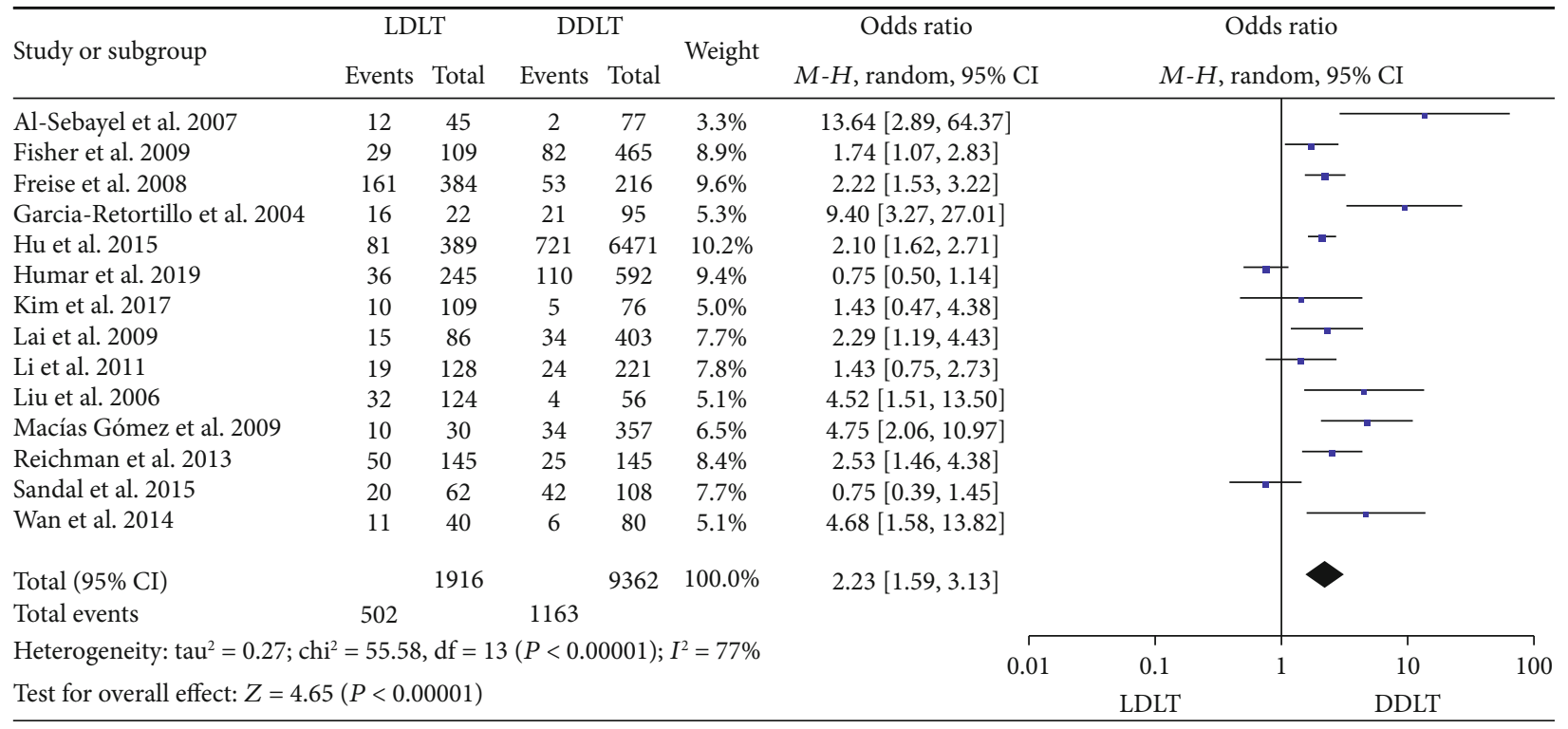

FIGURE 9: Meta-analysis of studies comparing the biliary complication rate between LDLT and DDLT recipients based on a random-effect model. LDLT: living donor liver transplantation; DDLT: deceased donor liver transplantation.

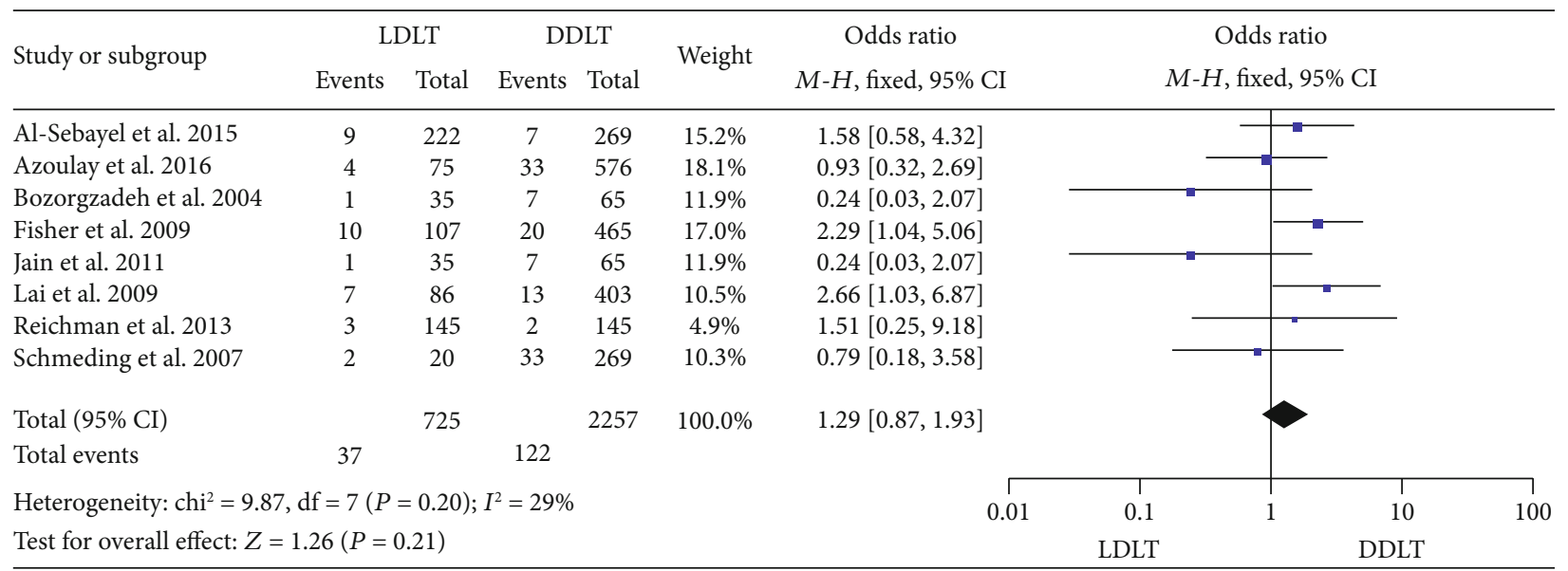

FIGURE 10: Meta-analysis of studies comparing the retransplantation rate between LDLT and DDLT recipients based on a fixed-effect model. LDLT: living donor liver transplantation; DDLT: deceased donor liver transplantation.

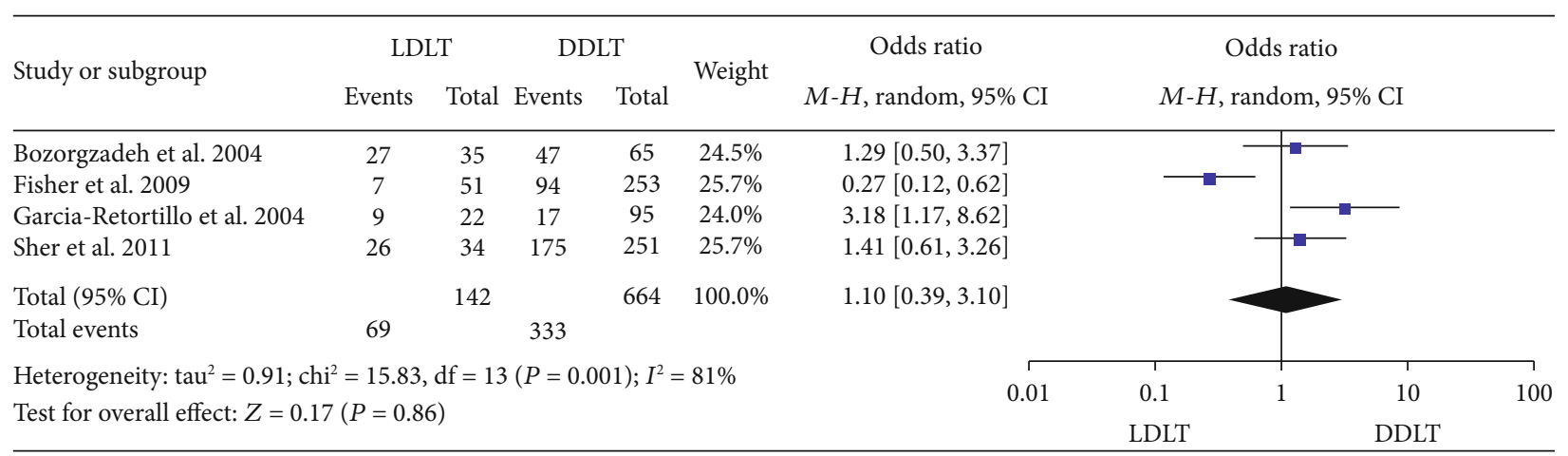

FIGURE 11: Meta-analysis of studies comparing HCV recurrence rate between LDLT and DDLT recipients based on a random-effect model. $\mathrm{HCV}$ : hepatitis C virus; LDLT: living donor liver transplantation; DDLT: deceased donor liver transplantation. 


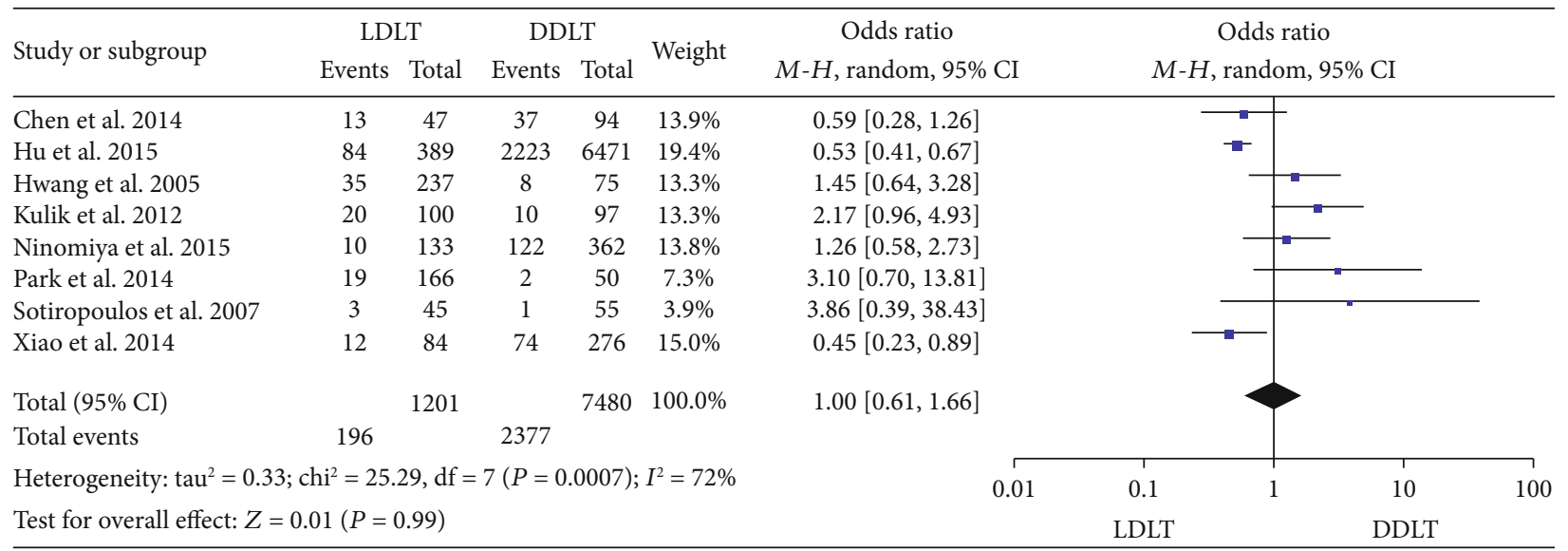

FIGURE 12: Meta-analysis of studies comparing 1-year HCC recurrence rate between LDLT and DDLT recipients based on a random-effect model. HCC: hepatocellular carcinoma; LDLT: living donor liver transplantation; DDLT: deceased donor liver transplantation.

\begin{tabular}{|c|c|c|c|c|c|c|c|c|c|}
\hline \multirow{3}{*}{$\begin{array}{l}\text { Study or subgroup } \\
\text { Hu et al. } 2015\end{array}$} & \multicolumn{2}{|c|}{ LDLT } & \multicolumn{2}{|c|}{ DDLT } & \multirow{2}{*}{ Weight } & \multirow{2}{*}{$\begin{array}{c}\text { Odds ratio } \\
M-H \text {, random, } 95 \% \mathrm{CI}\end{array}$} & \multirow{2}{*}{\multicolumn{2}{|c|}{$\begin{array}{c}\text { Odds ratio } \\
M-H \text {, random, } 95 \% \text { CI }\end{array}$}} & \\
\hline & \multirow{2}{*}{$\frac{\text { Events }}{141}$} & \multirow{2}{*}{$\begin{array}{c}\text { Total } \\
389\end{array}$} & \multirow{2}{*}{$\frac{\text { Events }}{3325}$} & \multirow{2}{*}{$\begin{array}{l}\text { Total } \\
6471\end{array}$} & & & & & \\
\hline & & & & & $27.0 \%$ & $0.54[0.44,0.67]$ & - & \multirow[b]{2}{*}{$\longrightarrow$} & \\
\hline Kulik et al. 2012 & 34 & 100 & 19 & 97 & $19.1 \%$ & $2.11[1.10,4.05]$ & & & \\
\hline Ninomiya et al. 2015 & 18 & 133 & 50 & 362 & $20.5 \%$ & $0.98[0.55,1.74]$ & 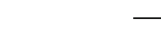 & & \\
\hline Sotiropoulos et al. 2007 & 5 & 45 & 10 & 55 & $11.2 \%$ & $0.56[0.18,1.79]$ & \multirow[b]{2}{*}{$\longrightarrow$} & & \\
\hline Xiao et al. 2014 & 37 & 84 & 140 & 276 & $22.2 \%$ & $0.76[0.47,1.25]$ & & & \\
\hline Total $(95 \% \mathrm{CI})$ & \multirow{2}{*}{\multicolumn{2}{|c|}{235}} & & 7261 & $100.0 \%$ & $0.86[0.52,1.41]$ & & & \\
\hline Total events & & & \multicolumn{2}{|l|}{3544} & & & & & \\
\hline \multicolumn{6}{|c|}{ Heterogeneity: tau $^{2}=0.23 ; \mathrm{chi}^{2}=18.06, \mathrm{df}=4(P=0.001) ; I^{2}=78 \%$} & \multirow[t]{2}{*}{0.01} & 0.1 & 10 & 100 \\
\hline Test for overall effect: $Z=$ & $61(P=0$ & $.54)$ & & & & & LDLT & DDLT & \\
\hline
\end{tabular}

FIGURE 13: Meta-analysis of studies comparing 3-year HCC recurrence rate between LDLT and DDLT recipients based on a random-effect model. HCC: hepatocellular carcinoma; LDLT: living donor liver transplantation; DDLT: deceased donor liver transplantation.

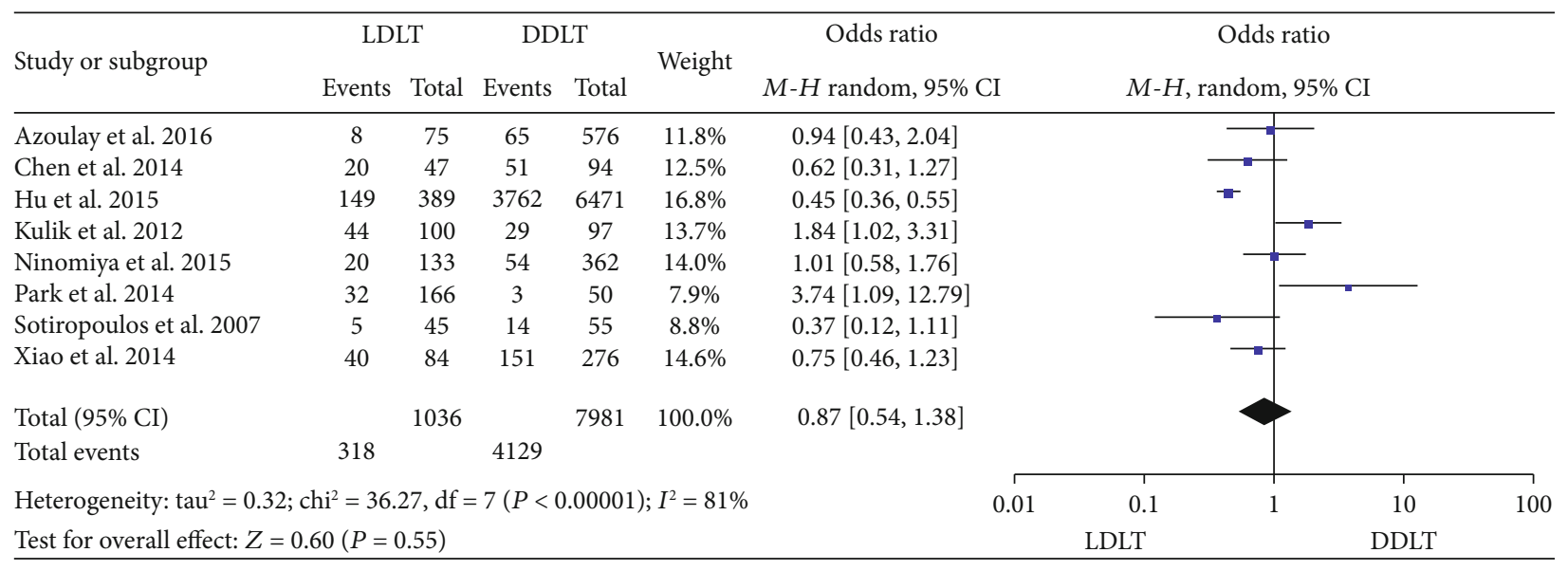

FIgURE 14: Meta-analysis of studies comparing 5-year HCC recurrence rate between LDLT and DDLT recipients based on a random-effect model. HCC: hepatocellular carcinoma; LDLT: living donor liver transplantation; DDLT: deceased donor liver transplantation.

47] reported 3-year OS. Two [14, 16] suggested a significantly higher 3-year OS in LDLT, and the rest $[4,10,11,15,21,25-$ $30,35,47]$ showed no significant difference between LDLT and DDLT. A random-effect model revealed a significantly higher 3-year OS in LDLT $(\mathrm{OR}=1.39,95 \% \mathrm{CI}=1.14$ to
1.69, $P=0.0010$; Figure 16). Sixteen studies [4, 11, 14-16, $21,26-30,32,34,35,41,44]$ reported 5-year OS. Three studies $[14,16,29]$ suggested a significantly higher 5 -year OS in LDLT, and the rest $[4,11,15,21,26-28,30,32,34,35,41$, 44] showed comparable OS between LDLT and DDLT. A 


\begin{tabular}{|c|c|c|c|c|c|c|c|c|c|}
\hline \multirow{2}{*}{ Study or subgroup } & \multicolumn{2}{|c|}{ LDLT } & \multicolumn{2}{|c|}{ DDLT } & \multirow{2}{*}{ Weight } & \multirow[b]{2}{*}{$M-H$, random, $95 \%$ CI } & \multirow{2}{*}{\multicolumn{2}{|c|}{$\begin{array}{c}\text { Odds ratio } \\
M-H, \text { random, } 95 \% \text { CI }\end{array}$}} & \\
\hline & Events & Total & Events & Total & & & & & \\
\hline Bhangui et al. 2011 & 31 & 36 & 108 & 120 & $3.7 \%$ & $0.69[0.23,2.11]$ & & & \\
\hline Bozorgzadeh et al. 2004 & 32 & 35 & 60 & 65 & $2.4 \%$ & $0.89[0.20,3.96]$ & & & \\
\hline Chen et al. 2014 & 41 & 47 & 73 & 94 & $4.4 \%$ & $1.97[0.73,5.26]$ & & & \\
\hline Fisher et al. 2009 & 88 & 107 & 400 & 465 & $7.3 \%$ & $0.75[0.43,1.32]$ & & & \\
\hline Gallegos-Orozco et al. 2009 & 29 & 32 & 160 & 168 & $2.8 \%$ & $0.48[0.12,1.93]$ & & & \\
\hline Hu et al. 2015 & 338 & 389 & 4801 & 6471 & $9.5 \%$ & $2.31[1.71,3.11]$ & & $\rightarrow$ & \\
\hline Hwang et al. 2005 & 174 & 237 & 46 & 75 & $7.4 \%$ & $1.74[1.01,3.01]$ & & & \\
\hline Jain et al. 2011 & 32 & 35 & 59 & 65 & $2.6 \%$ & $1.08[0.25,4.63]$ & & & \\
\hline Kim et al. 2017 & 97 & 109 & 55 & 76 & $5.6 \%$ & $3.09[1.41,6.75]$ & & & \\
\hline Ninomiya et al. 2015 & 124 & 133 & 301 & 362 & $6.0 \%$ & $2.79[1.34,5.80]$ & & & \\
\hline Russo et al. 2004 & 243 & 279 & 3441 & 3955 & $9.0 \%$ & $1.01[0.70,1.45]$ & & 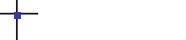 & \\
\hline Sebayel et al. 2015 & 193 & 222 & 232 & 269 & $7.7 \%$ & $1.06[0.63,1.79]$ & & - & \\
\hline Shah et al. 2007 & 140 & 154 & 326 & 350 & $6.3 \%$ & $0.74[0.37,1.47]$ & & - & \\
\hline Shen et al. 2011 & 35 & 38 & 57 & 67 & $2.8 \%$ & $2.05[0.53,7.95]$ & & & \\
\hline Sotiropoulos et al. 2007 & 30 & 45 & 45 & 55 & $4.7 \%$ & $0.44[0.18,1.12]$ & & & \\
\hline Terrault et al. 2014 & 166 & 195 & 144 & 180 & $7.5 \%$ & $1.43[0.84,2.45]$ & &. & \\
\hline Wan et al. 2014 & 36 & 40 & 68 & 80 & $3.4 \%$ & $1.59[0.48,5.28]$ & & & \\
\hline Xiao et al. 2014 & 69 & 84 & 191 & 276 & $6.9 \%$ & $2.05[1.11,3.78]$ & & & \\
\hline Total $(95 \% \mathrm{CI})$ & & 2217 & & 13193 & $100.0 \%$ & $1.32[1.01,1.72]$ & & 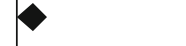 & \\
\hline Total events & 1898 & & 10567 & & & & & & \\
\hline Heterogeneity: $\operatorname{tau}^{2}=0.17 ; \mathrm{c}$ & $=43.62$, & $\mathrm{df}=17$ & $(P=0$ & $004) ; I^{2}$ & ${ }^{2}=61 \%$ & 0.01 & 0.1 & 10 & 100 \\
\hline Test for overall effect: $Z=2$. & $(P=0.04$ & & & & & & LDLT & DDLT & \\
\hline
\end{tabular}

FIGURE 15: Meta-analysis of studies comparing 1-year OS between LDLT and DDLT recipients based on a random-effect model. OS: overall survival; LDLT: living donor liver transplantation; DDLT: deceased donor liver transplantation.

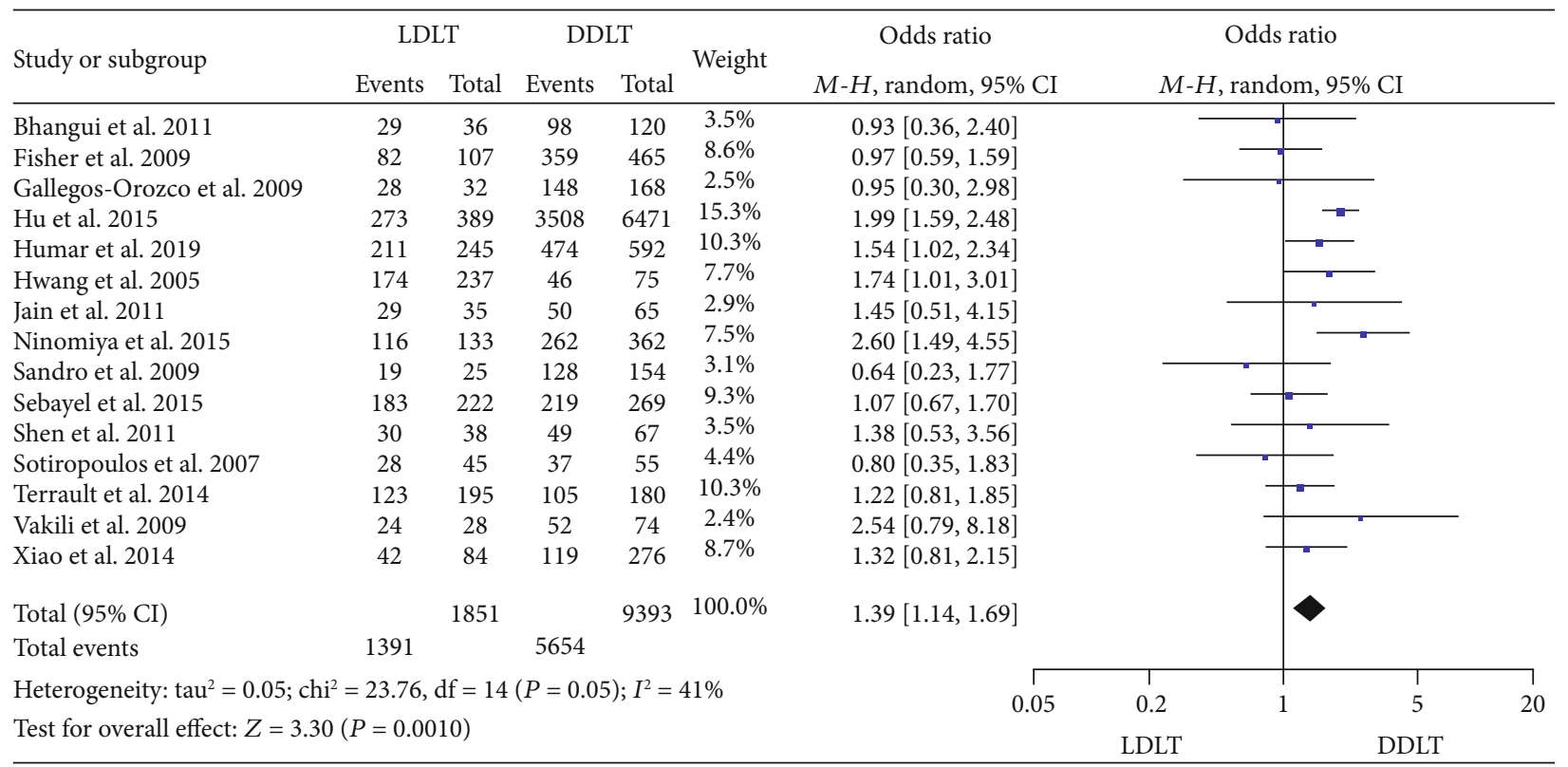

FIGURE 16: Meta-analysis of studies comparing 3-year OS between LDLT and DDLT recipients based on a random-effect model. OS: overall survival; LDLT: living donor liver transplantation; DDLT: deceased donor liver transplantation.

random-effect model revealed a significantly higher 5-year OS in $\operatorname{LDLT}(\mathrm{OR}=1.33,95 \% \mathrm{CI}=1.04$ to $1.70, P=0.02$; Figure 17). Significant heterogeneity was observed (1 year: $P=0.0004, I^{2}=61 \% ; 3$ years: $P=0.05, I^{2}=41 \%$; and 5 years: $\left.P<0.0001, I^{2}=66 \%\right)$.

3.14. Subgroup Analysis. To investigate the source of heterogeneity among studies, a subgroup analysis was carried out by stratifying the analysis according to several important factors, including study design, sample size, transplantation area, and patient diagnosis (Table 3 ). Moreover, to probe into the effect of sample size on the vascular complication rate, a subgroup was performed for it through insignificant heterogeneity. Most subgroup results were in line with the main results, while stratification of OS showed several points of discordance. Notably, according to the subgroup analysis, 


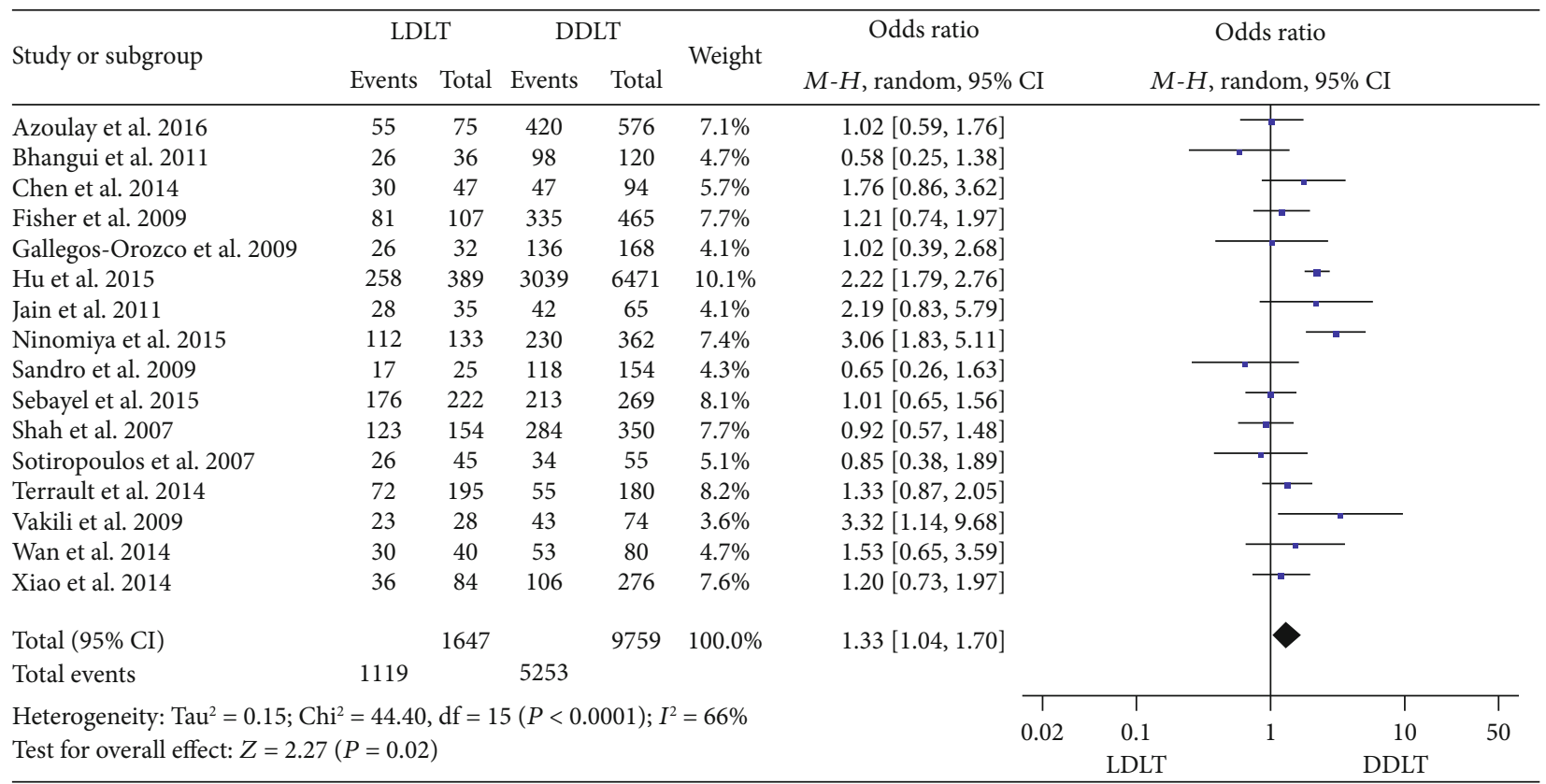

FIGURE 17: Meta-analysis of studies comparing 5-year OS between LDLT and DDLT recipients based on a random-effect model. OS: overall survival; LDLT: living donor liver transplantation; DDLT: deceased donor liver transplantation.

the ORs of OS were significantly higher and the OR of the biliary complication rate was significantly lower in subgroups with a bigger sample size, while this phenomenon could not be observed in the vascular complication rate. It indicated that $\mathrm{OS}$ and the biliary complication rate might dramatically improve as the centers' experience increased, while the disparity between the vascular complication rate of LDLT and that of DDLT was mainly caused by the difference of the donor type itself, and thus, it could not be improved with an accumulation of experience.

3.15. Publication Bias Assessment and Sensitivity Analysis. There was no evidence of publication bias for RBC transfusion, DRO, postoperative intra-abdominal bleeding rate, perioperative mortality, length of hospital stay, vascular complication rate, retransplantation rate, $\mathrm{HCV}$ recurrence rate, HCC recurrence rate (5-year), and OS, with a symmetrical appearance on funnel plots. For CIT, biliary complication rate and HCC recurrence rate (1- and 3-year), funnel plots showed an asymmetry which suggested that negative studies might be less reported. According to the sensitivity analysis, most of the overall results did not change after the exclusion of a single study except vascular complication rate, HCC recurrence (3-year), and OS (1- and 5-year).

\section{Discussion}

LDLT, which can provide a large pool of organs, is widely perceived as an alternative to DDLT for overcoming the scarcity of liver grafts. The survival of patients with end-stage liver diseases has been hugely improved with the advent of LDLT in the past decades. Furthermore, for emergency patients with fulminant hepatic failure, LDLT is also the optimal choice to timely save the patients' lives given the lack of deceased donor grafts [48]. However, LDLT involves a healthy donor, and the median mortality and morbidity of a donation are $0.2 \%$ and $16.1 \%$ [49]. It brings up controversies and ethical problems. Whether LDLT can provide comparable or better outcomes than DDLT is particularly important to the ethical acceptance and development of LDLT. Thus, with the aim of clarifying this issue and providing doctors and patients a reference to consider the riskbenefit balance, we conducted this study.

Currently, no satisfactory treatment is available to eradicate $\mathrm{HCV}$ infection; HCV recurrence is an important outcome related to the long-term survival of patients and usually occurrs around 0.5-1.5 years after LT [24, 50]. Whether the difference of donor types influenced the recurrence rate after transplantation was controversial. Related studies [51-54] indicated a rapid regeneration of hepatocytes caused by a compensatory regenerative process after LDLT, and better human leukocyte antigen (HLA) matching between donor and recipient might facilitate intrahepatocyte $\mathrm{HCV}$ proliferation; the former was verified in vitro, where a higher HCV internal ribosome entry site activity and replication were found in actively dividing cells $[55,56]$. Contrarily, some other studies [57-59] thought less immunosuppression dose and acute cellular rejection (ACR) after LDLT might reduce HCV recurrence rate. In our study, the synthesis of the aforementioned factors showed a similar recurrence rate between LDLT and DDLT.

Whether HCC recurrence is more frequent in LDLT remains controversial. Independent risk factors of HCC recurrence after LT for HCC included tumor size (exceeding $5 \mathrm{~cm}$ in diameter), low-grade histologic differentiation, and gross invasion of major hepatic vessels [25]. Furthermore, Park et al. [33] believed that LDLT itself was an independent risk factor of HCC recurrence. At present, the following 
TABle 3: Subgroup analysis.

\begin{tabular}{|c|c|c|c|c|c|c|}
\hline Outcomes & Subgroup & Studies $(n)$ & Effect estimate (95\% CI) & $P$ value & Heterogeneity & $\begin{array}{l}\text { Inconsistency } \\
\text { with the } \\
\text { overall results }\end{array}$ \\
\hline \multirow{3}{*}{ CIT } & DDLT $<400$ & 3 & $-371.10(-373.60,-368.60)$ & $P<0.00001$ & $P=0.20, I^{2}=37 \%$ & \\
\hline & DDLT $\geq 400$ & 3 & $-372.02(-445.71,-298.34)$ & $P<0.00001$ & $P<0.00001, I^{2}=97 \%$ & \\
\hline & Overall & 6 & $-373.39(-399.41,-347.37)$ & $P<0.00001$ & $P<0.00001, I^{2}=96 \%$ & \\
\hline \multirow{3}{*}{$\begin{array}{l}\text { Vascular complication } \\
\text { rates }\end{array}$} & LDLT $<100$ & 3 & $1.05(0.51,2.16)$ & $P=0.89$ & $P=0.24, I^{2}=30 \%$ & Equivalent \\
\hline & LDLT $\geq 100$ & 3 & $2.89(1.62,5.16)$ & $P=0.0003$ & $P=0.26, I^{2}=26 \%$ & \\
\hline & Overall & 6 & $2.00(1.31,3.07)$ & $P=0.001$ & $P=0.11, I^{2}=45 \%$ & \\
\hline \multirow{7}{*}{ Biliary complication rates } & LDLT $<100$ & 6 & $3.71(1.58-8.71)$ & $P=0.003$ & $P<0.0001, I^{2}=82 \%$ & \\
\hline & $\mathrm{LDLT} \geq 100$ & 8 & $1.77(1.27,2.48)$ & $P=0.0008$ & $P=0.0008, I^{2}=72 \%$ & \\
\hline & DDLT $<100$ & 5 & $4.80(2.88-7.98)$ & $P<0.00001$ & $P=0.10, I^{2}=49 \%$ & \\
\hline & $\operatorname{DDLT} \geq 100$ & 9 & $1.74(1.24-2.43)$ & $P=0.001$ & $P<0.0001, I^{2}=77 \%$ & \\
\hline & HCC related & 2 & $2.21(1.72,2.83)$ & $P<0.00001$ & $P=0.16, I^{2}=50 \%$ & \\
\hline & Not HCC related & 12 & $2.21(1.46,3.34)$ & $P=0.0002$ & $P<0.00001, I^{2}=79 \%$ & \\
\hline & Overall & 14 & $2.23(1.59,3.13)$ & $P<0.00001$ & $P<0.0001, I^{2}=77 \%$ & \\
\hline \multirow{3}{*}{ HCV recurrence } & DDLT $<100$ & 2 & $1.92(0.95,3.87)$ & $P=0.07$ & $P=0.20, I^{2}=39 \%$ & \\
\hline & DDLT $\geq 100$ & 2 & $0.62(0.12,3.15)$ & $P=0.56$ & $P=0.006, I^{2}=87 \%$ & \\
\hline & Overall & 4 & $1.10(0.39,3.10)$ & $P=0.86$ & $P=0.001, I^{2}=81 \%$ & \\
\hline \multirow{3}{*}{ 1-year HCC recurrence } & LDLT $<100$ & 3 & $0.56(0.35,0.91)$ & $P=0.02$ & $P=0.21, I^{2}=35 \%$ & Favors LDLT \\
\hline & $\mathrm{LDLT} \geq 100$ & 5 & $1.29(0.62,2.71)$ & $P=0.49$ & $P=0.0002, I^{2}=81 \%$ & \\
\hline & Overall & 8 & $1.00(0.61,1.66)$ & $P=0.99$ & $P=0.0007, I^{2}=72 \%$ & \\
\hline \multirow{3}{*}{ 3-year HCC recurrence } & $\mathrm{LDLT}<100$ & 2 & $0.73(0.46,1.14)$ & $P=0.17$ & $P=63, I^{2}=0 \%$ & \\
\hline & $\mathrm{LDLT} \geq 100$ & 3 & $0.99(0.44,2.23)$ & $P=0.98$ & $P=0.0002, I^{2}=89 \%$ & \\
\hline & Overall & 5 & $0.86(0.52,1.41)$ & $P=0.54$ & $P=0.001, I^{2}=78 \%$ & \\
\hline \multirow{3}{*}{ 5-year HCC recurrence } & $\mathrm{LDLT}<100$ & 4 & $0.70(0.50,0.98)$ & $P=0.04$ & $P=0.56, I^{2}=0 \%$ & Favors LDLT \\
\hline & $\mathrm{LDLT} \geq 100$ & 4 & $1.19(0.49,2.90)$ & $P=0.70$ & $P<0.00001, I^{2}=91 \%$ & \\
\hline & Overall & 8 & $0.87(0.54,1.38)$ & $P=0.55$ & $P<0.00001, I^{2}=81 \%$ & \\
\hline \multirow{5}{*}{ 1-year OS } & $\mathrm{LDLT}<100$ & 9 & $1.27(0.90,1.77)$ & $P=0.17$ & $P=0.15, I^{2}=33 \%$ & Equivalent \\
\hline & $\mathrm{LDLT} \geq 100$ & 9 & $1.43(1.02,2.01)$ & $P=0.04$ & $P=0.0002, I^{2}=74 \%$ & \\
\hline & HCC related & 9 & $1.68(1.19,2.37)$ & $P=0.003$ & $P=0.05, I^{2}=49 \%$ & \\
\hline & Not HCC related & 9 & $1.07(0.87,1.32)$ & $P=0.50$ & $P=0.14, I^{2}=35 \%$ & Equivalent \\
\hline & Overall & 18 & $1.32(1.01,1.72)$ & $P=0.04$ & $P=0.0004, I^{2}=61 \%$ & \\
\hline \multirow{5}{*}{ 3-year OS } & LDLT $<100$ & 8 & $1.17(0.87,1.58)$ & $P=0.29$ & $P=0.70, I^{2}=0 \%$ & Equivalent \\
\hline & $\mathrm{LDLT} \geq 100$ & 7 & $1.52(1.18,1.95)$ & $P=0.001$ & $P=0.02, I^{2}=60 \%$ & \\
\hline & HCC related & 9 & $1.55(1.17,2.04)$ & $P=0.002$ & $P=0.08, I^{2}=43 \%$ & \\
\hline & Not HCC related & 6 & $1.21(0.98,1.50)$ & $P=0.07$ & $P=0.75, I^{2}=0 \%$ & Equivalent \\
\hline & Overall & 15 & $1.39(1.14,1.69)$ & $P=0.0010$ & $P=0.05, I^{2}=41 \%$ & \\
\hline \multirow{5}{*}{ 5-year OS } & LDLT $<100$ & 10 & $1.20(0.95,1.52)$ & $P=0.13$ & $P=0.22, I^{2}=24 \%$ & Equivalent \\
\hline & $\mathrm{LDLT} \geq 100$ & 6 & $1.49(1.02,2.16)$ & $P=0.04$ & $P<0.0001, I^{2}=81 \%$ & \\
\hline & HCC related & 10 & $1.43(1.01,2.03)$ & $P=0.05$ & $P=0.0003, I^{2}=71 \%$ & \\
\hline & Not HCC related & 6 & $1.15(0.92,1.42)$ & $P=0.21$ & $P=0.64, I^{2}=0 \%$ & Equivalent \\
\hline & Overall & 16 & $1.33(1.04,1.70)$ & $P=0.02$ & $P<0.0001, I^{2}=66 \%$ & \\
\hline
\end{tabular}


reasons were thought to cause a higher HCC recurrence in LDLT. First, with a short and inadequate waiting time before LDLT, the aggressiveness of tumor biology might not be readily recognized and clinically undetectable micrometastases or vascular invasion might not become apparent; this is called the "test of time" [37, 60-62]. As a result, a higher recurrence rate was induced in LDLT recipients than in DDLT recipients who had a relatively longer waiting time. This hypothesis was supported by some studies. Kulik and Abecassis [63] found a 15\% HCC recurrence rate in patients with a $\mathrm{T}_{1}$ or $\mathrm{T}_{2}$ stage in the short waiting time group that was sharply in contrast to $0 \%$ in patients with $\mathrm{T}_{3}$ or $\mathrm{T}_{4}$ tumors in the long-waiting-time group. Moreover, significant activation of cell signaling pathways which led to tumor migration and invasion in small size grafts was demonstrated to promote tumor growth and metastasis after LT in an animal study [64]. Second, the regeneration of liver grafts is a natural course after LDLT [65]. However, the rapid regeneration of the liver might release more upregulation factors such as growth factors and cytokines, which might establish a favorable environment for tumor progression in cases of persistent occult extrahepatic tumor foci and accelerate the growth of tumor cells; this progress finally increases the HCC recurrence rate in LDLT $[66,67]$. Third, it was thought that LDLT was more likely to result in acute phase graft injury in low graft recipient weight ratio LT, which might lead to cell adhesion, angiogenesis, and migration and provide a more favorable environment for the growth of tumor cells [68, 69]. Fourth, the greater bile duct and hepatic artery length and the preservation of vena cava in LDLT recipients might leave residual tumor or violate the tumor capsule; the greater manipulation of the livers might also lead to tumor embolus detachment through the hepatic veins [44]. Although numerous theories support the fact that LDLT recipients suffered a higher HCC recurrence rate, slight but not significantly lower 1-, 3-, and 5-HCC recurrence rates in LDLT were observed in our study. It was confusing, and some opposite factors must work in this process. Further studies at the molecular or genetic level are needed.

Postoperative biliary complications have been commonly viewed as the "Achilles heel" of LT [70], and concern about an increased risk for biliary complications in LDLT has been a worry. Although a short CIT and decreased ACR in LDLT could reduce the occurrence of biliary complications $[58,71$, 72], numerous studies still indicate higher biliary complications in LDLT recipients for technical factors. Some studies have shown that biliary complications could be decreased dramatically with increased experience [40,73-75]. We have seen this also in the subgroup analysis; the OR of the biliary complication rate of a bigger sample size group was much lower than that of a smaller sample size group. It indicated that greater experience was critical in considerably minimizing the technical complications in LDLT. Except for the learning curve, other possible explanations for a higher biliary complication rate in LDLT included inferior quality of the LDLT grafts [76-82], high frequency of double or multiple biliary anastomoses, high Model for End-stage Liver Disease (MELD) score associated with relatively inadequate arterial perfusion [83], and dislodgement of the biliary drain- age tube or biliary leakage after removal of the tube [84]. Fortunately, biliary complications might not be lethal in most situations for the application of radiological interventions [85].

Postoperative vascular complications, especially hepatic artery problems, were another major surgical morbidity. In our study, LDLT was associated with a significantly higher rate of vascular complications. This might be due to insufficient length for reconstruction, smaller vessel diameter, and greater risk of a twist of the vascular pedicle of LDLT grafts [86]. Different from biliary complications, vascular complications did not decrease as centers gained greater experience. This might indicate that the higher vascular complication rate was mainly caused by the difference of donor types itself and could not be reduced with an accumulation of experience. Further studies are needed to explain this issue.

In our study, pooled patient OS were significantly better in LDLT recipients. It might be related to a better quality of living grafts and better conditions of the patients when receiving LT. Most studies showed that the mean donor age was significantly higher in DDLT, while the use of grafts from donors older than 40 to 50 years of age has been proven to result in poor patient survival [87, 88]. Simultaneously, DDLT groups had notably higher MELD scores and longer waiting time; this generally resulted in a more debilitated overall state by the time the patients received LT [10] and finally had a negative impact on patients' survival. Moreover, ACR, which was less in LDLT for better HLA matching, was also identified as a negative factor in DDLT [35, 89-91]. It is worth highlighting here that OS of LDLT patients improved dramatically as centers' LDLT experience increased. When detecting significant heterogeneity in the synthesis of OS by LDLT size $(<100$ or $\geq 100)$, the ORs of OS were significantly greater in subgroups with a bigger size. It indicated that centers' LDLT experience greatly influenced the patient's OS and "learning curve" might contribute in OS. Improvements in patient selection and technical advances might account for the improved OS in experienced centers.

Besides, LDLT had a significantly shorter CIT and lower postoperative intra-abdominal bleeding rate. A long CIT was related to late biliary complications $[71,72]$ and was a significant predictor of the overall risk of graft failure [40], while a short CIT could reduce the severity of hepatocellular injury in the early postoperative period as measured by the peak serum aspartate aminotransferase and alanine aminotransferase levels [31]. Lower postoperative intra-abdominal bleeding rate in LDLT might be due to the higher quality of living graft. Furthermore, whether a difference of coagulation function existed in different donor types was worth investigating deeply. Notably, perioperative mortality did not decrease in LDLT though there was a significantly lower postoperative intra-abdominal bleeding rate.

However, we have to acknowledge some limitations in our study. First, the definition of some complications were not clear or uniform in different studies. Second, the existence of significant heterogeneity in several outcomes could not be explained well enough by subgroup analysis. Third, included studies were conducted in different regions where policies and ethics about LT were different, and this might 
cause potential bias. Moreover, studies based on databases were included in our meta-analysis, and this might cause unknown overlapping of data.

In conclusion, this meta-analysis represents the latest and the most comprehensive comparison of LDLT and DDLT. Our study demonstrated that LDLT was not inferior to DDLT in consideration of RBC transfusion, length of hospital stay, perioperative mortality, retransplantation rate, $\mathrm{HCV}$ recurrence rate, and HCC recurrence rate, but it was an improvement in CIT, postoperative intra-abdominal bleeding rate, and OS. Therefore, LDLT remains a valuable option for patients in need of LT for it provides an excellent alternative to DDLT; the application of LDLT should be considered more especially in areas with an extremely limited deceased donor pool. However, there is a significantly higher incidence of biliary and vascular complications associated with LDLT. Further refinement in biliary and vascular reconstruction techniques and the accumulation of LT centers' experience are the key factors in expanding the application of LDLT.

\section{Abbreviations \\ ACR: Acute cellular rejection \\ CI: Confidence interval \\ CIT: Cold ischemia time \\ DDLT: Deceased donor liver transplantation \\ DRO: Duration of the recipient operation \\ HCC: Hepatocellular carcinoma \\ $\mathrm{HCV}$ : Hepatitis $\mathrm{C}$ virus \\ HLA: Human leukocyte antigen \\ LDLT: Living donor liver transplantation \\ LT: $\quad$ Liver transplantation \\ MD: $\quad$ Mean difference \\ MELD: Model for end-stage liver disease \\ OR: Odds ratio \\ OS: Overall survival \\ RBC: $\quad$ Red blood cell.}

\section{Conflicts of Interest}

The authors declared no potential conflicts of interest.

\section{Authors' Contributions}

Wei Tang and Jian-Guo Qiu performed the study and wrote the paper. Yang Cai and Luo Cheng collected and analyzed the data and made the tables and figures. Cheng-You Du designed the study, edited the manuscript, and offered suggestions for this study. Wei Tang and Jian-Guo Qiu contributed equally to this work.

\section{Acknowledgments}

The authors thank the staff and colleagues in the Chinese Cochrane Center for their help and support. This study was funded by the National Natural Science Foundation of China (81703063 and 81702408) and the Basic Research and Frontier Exploration Project of Chongqing Science and Technology Commission (cstc2017jcyjBX0010 and cstc2018jcyjAX0825).

\section{Supplementary Materials}

We submitted supporting information to help improve and prove the reporting quality of our study. These include the PRISMA 2009 checklist and the PRISMA 2009 flow diagram. (Supplementary Materials)

\section{References}

[1] M. Guba, L. Adcock, C. MacLeod et al., "Intraoperative "no go" donor hepatectomies in living donor liver transplantation," American Journal of Transplantation, vol. 10, no. 3, pp. 612-618, 2010.

[2] M. R. Foxton, M. A. B. al-Freah, A. J. Portal et al., "Increased model for end-stage liver disease score at the time of liver transplant results in prolonged hospitalization and overall intensive care unit costs," Liver Transplantation, vol. 16, no. 5, pp. 668-677, 2010.

[3] J. M. Llovet and J. Bruix, "Novel advancements in the management of hepatocellular carcinoma in 2008," Journal of Hepatology, vol. 48, Suppl 1, pp. S20-S37, 2008.

[4] P. Bhangui, E. Vibert, P. Majno et al., "Intention-to-treat analysis of liver transplantation for hepatocellular carcinoma: living versus deceased donor transplantation," Hepatology, vol. 53, no. 5, pp. 1570-1579, 2011.

[5] A. Dagradi, P. F. Munari, A. Gamba, M. Zannini, P. L. Sussi, and G. Serio, "Problems of surgical anatomy and surgical practice studied with a view to transplantation of sections of the liver in humans," Chirurgia Italiana, vol. 18, no. 4, pp. 639659, 1966.

[6] R. W. Strong, S. V. Lynch, T. H. Ong, H. Matsunami, Y. Koido, and G. A. Balderson, "Successful liver transplantation from a living donor to her son," The New England Journal of Medicine, vol. 322, no. 21, pp. 1505-1507, 1990.

[7] A. Stang, "Critical evaluation of the Newcastle-Ottawa scale for the assessment of the quality of nonrandomized studies in meta-analyses," European Journal of Epidemiology, vol. 25, no. 9, pp. 603-605, 2010.

[8] S. P. Hozo, B. Djulbegovic, and I. Hozo, "Estimating the mean and variance from the median, range, and the size of a sample," BMC Medical Research Methodology, vol. 5, no. 1, p. 13, 2005.

[9] J. P. T. Higgins and S. Green, "Cochrane handbook for systematic reviews of interventions," Journal of Multidisciplinary Evaluation, vol. 6, pp. 143-148, 2010.

[10] A. Humar, S. Ganesh, D. Jorgensen et al., “Adult living donor versus deceased donor liver transplant (LDLT versus DDLT) at a single center: time to change our paradigm for liver transplant," Annals of Surgery, vol. 270, no. 3, pp. 444-451, 2019.

[11] R. A. Fisher, A. H. Cotterell, D. G. Maluf et al., "Adult living donor versus deceased donor liver transplantation: a 10-year prospective single center experience," Annals of Hepatology, vol. 8, no. 4, pp. 298-307, 2009.

[12] L. Jiang, L. Yan, Y. Tan et al., “Adult-to-adult right-lobe living donor liver transplantation in recipients with hepatitis B virusrelated benign liver disease and high model end-stage liver disease scores," Surgery Today, vol. 43, no. 9, pp. 1039-1048, 2013.

[13] E. J. Kim, S. Lim, C. W. Chu et al., "Clinical impacts of donor types of living vs. deceased donors: predictors of one-year mortality in patients with liver transplantation," Journal of Korean Medical Science, vol. 32, no. 8, pp. 1258-1262, 2017. 
[14] Z. Hu, Z. Qian, J. Wu et al., "Clinical outcomes and risk factors of hepatocellular carcinoma treated by liver transplantation: a multi-centre comparison of living donor and deceased donor transplantation," Clinics and Research in Hepatology and Gastroenterology, vol. 40, no. 3, pp. 315-326, 2016.

[15] A. Jain, A. Singhal, R. Kashyap, S. Safadjou, C. K. Ryan, and M. S. Orloff, "Comparative analysis of hepatitis $\mathrm{C}$ recurrence and fibrosis progression between deceased-donor and livingdonor liver transplantation: 8-year longitudinal follow-up," Transplantation, vol. 92, no. 4, pp. 453-460, 2011.

[16] M. Ninomiya, K. Shirabe, M. E. Facciuto et al., "Comparative study of living and deceased donor liver transplantation as a treatment for hepatocellular carcinoma," Journal of the American College of Surgeons, vol. 220, no. 3, pp. 297-304.e3, 2015.

[17] S. Sandal, A. Almudevar, S. Parajuli, and A. Bose, "Comparing 10-yr renal outcomes in deceased donor and living donor liver transplants," Clinical Transplantation, vol. 29, no. 12, pp. 1140-1147, 2015.

[18] R. S. Hoehn, G. C. Wilson, K. Wima et al., "Comparing living donor and deceased donor liver transplantation: a matched national analysis from 2007 to 2012," Liver Transplantation, vol. 20, no. 11, pp. 1347-1355, 2014.

[19] C. Macías Gómez, J. M. Dumonceau, M. Marcolongo, E. Santibañes, and J. Dávolos, "Endoscopic management of biliary complications after adult living-donor versus deceaseddonor liver transplantation," Transplantation, vol. 88, no. 11, pp. 1280-1285, 2009.

[20] P. J. Thuluvath and H. Y. Yoo, "Graft and patient survival after adult live donor liver transplantation compared to a matched cohort who received a deceased donor transplantation," Liver Transplantation, vol. 10, no. 10, pp. 1263-1268, 2004.

[21] N. A. Terrault, R. T. Stravitz, A. S. F. Lok et al., "Hepatitis C disease severity in living versus deceased donor liver transplant recipients: an extended observation study," Hepatology, vol. 59, no. 4, pp. 1311-1319, 2014.

[22] M. Schmeding, U. P. Neumann, G. Puhl, M. Bahra, R. Neuhaus, and P. Neuhaus, "Hepatitis C recurrence and fibrosis progression are not increased after living donor liver transplantation: a single-center study of 289 patients," Liver Transplantation, vol. 13, no. 5, pp. 687-692, 2007.

[23] M. Garcia-Retortillo, X. Forns, J. M. Llovet et al., "Hepatitis C recurrence is more severe after living donor compared to cadaveric liver transplantation," Hepatology, vol. 40, no. 3, pp. 699-707, 2004.

[24] A. Bozorgzadeh, A. Jain, C. Ryan et al., "Impact of hepatitis C viral infection in primary cadaveric liver allograft versus primary living-donor allograft in 100 consecutive liver transplant recipients receiving tacrolimus," Transplantation, vol. 77, no. 7, pp. 1066-1070, 2004.

[25] S. Hwang, S. G. Lee, J. W. Joh, K. S. Suh, and D. G. Kim, "Liver transplantation for adult patients with hepatocellular carcinoma in Korea: comparison between cadaveric donor and living donor liver transplantations," Liver Transplantation, vol. 11, no. 10, pp. 1265-1272, 2005.

[26] G. C. Sotiropoulos, H. Lang, S. Nadalin et al., "Liver transplantation for hepatocellular carcinoma: University Hospital Essen experience and metaanalysis of prognostic factors," Journal of the American College of Surgeons, vol. 205, no. 5, pp. 661-675, 2007.

[27] M. Al Sebayel, F. Abaalkhail, A. Hashim et al., "Living donor liver transplant versus cadaveric liver transplant survival in relation to model for end-stage liver disease score," Transplantation Proceedings, vol. 47, no. 4, pp. 1211-1213, 2015.

[28] G. Q. Xiao, J. L. Song, S. Shen, J. Y. Yang, and L. N. Yan, "Living donor liver transplantation does not increase tumor recurrence of hepatocellular carcinoma compared to deceased donor transplantation," World Journal of Gastroenterology, vol. 20, no. 31, pp. 10953-10959, 2014.

[29] K. Vakili, J. J. Pomposelli, Y. L. Cheah et al., "Living donor liver transplantation for hepatocellular carcinoma: increased recurrence but improved survival," Liver Transplantation, vol. 15, no. 12, pp. 1861-1866, 2009.

[30] S. Di Sandro, A. O. Slim, A. Giacomoni et al., "Living donor liver transplantation for hepatocellular carcinoma: long-term results compared with deceased donor liver transplantation," Transplantation Proceedings, vol. 41, no. 4, pp. 1283-1285, 2009.

[31] T. W. Reichman, H. Katchman, T. Tanaka et al., "Living donor versus deceased donor liver transplantation: a surgeonmatched comparison of recipient morbidity and outcomes," Transplant International, vol. 26, no. 8, pp. 780-787, 2013.

[32] D. Azoulay, E. Audureau, P. Bhangui, J. Belghiti, and C. Feray, "Living or brain-dead donor liver transplantation for hepatocellular carcinoma: a multicenter, western, intent-to-treat cohort study," Annals of Surgery, vol. 266, no. 6, pp. 10351044, 2017.

[33] M. S. Park, K. W. Lee, S. W. Suh et al., "Living-donor liver transplantation associated with higher incidence of hepatocellular carcinoma recurrence than deceased-donor liver transplantation," Transplantation Journal, vol. 97, no. 1, pp. 7177, 2014.

[34] P. Wan, J. J. Zhang, Q. G. Li et al., "Living-donor or deceaseddonor liver transplantation for hepatic carcinoma: a casematched comparison," World Journal of Gastroenterology, vol. 20, no. 15, pp. 4393-4400, 2014.

[35] J. F. Gallegos-Orozco, A. Yosephy, B. Noble et al., "Natural history of post-liver transplantation hepatitis C: a review of factors that may influence its course," Liver Transplantation, vol. 15, no. 12, pp. 1872-1881, 2009.

[36] C. L. Liu, S. T. Fan, C. M. Lo et al., "Operative outcomes of adult-to-adult right lobe live donor liver transplantation: a comparative study with cadaveric whole-graft liver transplantation in a single center," Annals of Surgery, vol. 243, no. 3, pp. 404-410, 2006.

[37] L. M. Kulik, R. A. Fisher, D. R. Rodrigo et al., "Outcomes of living and deceased donor liver transplant recipients with hepatocellular carcinoma: results of the A2ALL cohort," American Journal of Transplantation, vol. 12, no. 11, pp. 2997-3007, 2012.

[38] C. Li, K. Mi, T. Wen et al., "Outcomes of patients with benign liver diseases undergoing living donor versus deceased donor liver transplantation," PLoS One, vol. 6, no. 11, article e27366, 2011.

[39] M. W. Russo, J. Galanko, K. Beavers, M. W. Fried, and R. Shrestha, "Patient and graft survival in hepatitis $\mathrm{C}$ recipients after adult living donor liver transplantation in the United States," Liver Transplantation, vol. 10, no. 3, pp. 340-346, 2004.

[40] C. E. Freise, B. W. Gillespie, A. J. Koffron et al., "Recipient morbidity after living and deceased donor liver transplantation: findings from the A2ALL Retrospective Cohort Study," American Journal of Transplantation, vol. 8, no. 12, pp. 2569-2579, 2008. 
[41] S. A. Shah, G. A. Levy, P. D. Greig et al., "Reduced mortality with right-lobe living donor compared to deceased-donor liver transplantation when analyzed from the time of listing," American Journal of Transplantation, vol. 7, no. 4, pp. 9981002, 2007.

[42] J. C. Lai, E. M. Pichardo, J. C. Emond, and R. S. Brown, "Resource utilization of living donor versus deceased donor liver transplantation is similar at an experienced transplant center," American Journal of Transplantation, vol. 9, no. 3, pp. 586-591, 2009.

[43] N. Selzner, N. Girgrah, L. Lilly et al., "The difference in the fibrosis progression of recurrent hepatitis $\mathrm{C}$ after live donor liver transplantation versus deceased donor liver transplantation is attributable to the difference in donor age," Liver Transplantation, vol. 14, no. 12, pp. 1778-1786, 2008.

[44] J. Chen, X. Xu, J. Wu et al., "The stratifying value of Hangzhou criteria in liver transplantation for hepatocellular carcinoma," PLoS One, vol. 9, no. 3, article e93128, 2014.

[45] M. Al-Sebayel, H. Khalaf, M. Al-Sofayan et al., "Experience with 122 consecutive liver transplant procedures at King Faisal Specialist Hospital and Research Center," Annals of Saudi Medicine, vol. 27, no. 5, pp. 333-338, 2007.

[46] L. Sher, L. Jennings, S. Rudich et al., "Results of live donor liver transplantation in patients with hepatitic $\mathrm{C}$ virus infection: the HCV 3 trial experience," Clinical Transplantation, vol. 26, no. 3, pp. 502-509, 2012.

[47] C. H. Shen, Q. Xia, N. Xu et al., "Living donor liver transplantation for adult patients with hepatocellular carcinoma," Journal of Hepatobiliary Surgery, vol. 19, no. 5, pp. 340-344, 2011.

[48] S. J. Kim, Y. C. Yoon, Y. K. Yoo, J. H. Park, and D. G. Kim, "Clinical analysis of emergency liver transplantation: the role of living donor liver transplantation," Clinical Transplantation, vol. 26, no. 6, pp. 833-841, 2012.

[49] P. Intaraprasong, A. Sobhonslidsuk, and S. Tongprasert, "Donor outcomes after living donor liver transplantation (LDLT)," Journal of the Medical Association of Thailand, vol. 93, no. 11, pp. 1340-1343, 2010.

[50] H. Van Vlierberghe, R. Troisi, I. Colle, S. Ricciardi, M. Praet, and B. de Hemptinne, "Hepatitis $\mathrm{C}$ infection-related liver disease: patterns of recurrence and outcome in cadaveric and living-donor liver transplantation in adults," Transplantation, vol. 77, no. 2, pp. 210-214, 2004.

[51] A. C. Baltz and J. F. Trotter, "Living donor liver transplantation and hepatitis C," Clinics in Liver Disease, vol. 7, no. 3, pp. 651-665, 2003.

[52] R. Manez, R. Mateo, J. Tabasco, S. Kusne, T. E. Starzl, and R. J. Duquesnoy, "The influence of HLA donor-recipient compatibility on the recurrence of HBV and HCV hepatitis after liver transplantation," Transplantation, vol. 59, no. 4, pp. 640-642, 1995.

[53] S. J. Cotler, L. K. Gaur, D. R. Gretch et al., "Donor-recipient sharing of HLA class II alleles predicts earlier recurrence and accelerated progression of hepatitis $\mathrm{C}$ following liver transplantation," Tissue Antigens, vol. 52, no. 5, pp. 435-443, 1998.

[54] A. Marcos, R. A. Fisher, J. M. Ham et al., "Liver regeneration and function in donor and recipient after right lobe adult to adult living donor liver transplantation," Transplantation, vol. 69 , no. 7, pp. 1375-1379, 2000.

[55] M. Honda, S. Kaneko, E. Matsushita, K. Kobayashi, G. A. Abell, and S. M. Lemon, "Cell cycle regulation of hepatitis C virus internal ribosomal entry site-directed translation," Gastroenterology, vol. 118, no. 1, pp. 152-162, 2000.
[56] F. Scholle, K. Li, F. Bodola, M. Ikeda, B. A. Luxon, and S. M. Lemon, "Virus-host cell interactions during hepatitis $\mathrm{C}$ virus RNA replication: impact of polyprotein expression on the cellular transcriptome and cell cycle association with viral RNA synthesis," Journal of Virology, vol. 78, no. 3, pp. 1513-1524, 2004.

[57] M. Takatsuki, S. Uemoto, Y. Inomata et al., "Weaning of immunosuppression in living donor liver transplant recipients," Transplantation, vol. 72, no. 3, pp. 449-454, 2001.

[58] L. U. Liu, C. A. Bodian, G. E. Gondolesi et al., "Marked differences in acute cellular rejection rates between living-donor and deceased-donor liver transplant recipients," Transplantation, vol. 80, no. 8, pp. 1072-1080, 2005.

[59] I. Kam, "Editorial. Adult-adult right hepatic lobe living donor liver transplantation for status 2 a patients: too little, too late," Liver Transplantation, vol. 8, no. 4, pp. 347-349, 2002.

[60] K. J. Halazun, R. E. Patzer, A. A. Rana et al., "Standing the test of time: outcomes of a decade of prioritizing patients with hepatocellular carcinoma, results of the UNOS natural geographic experiment," Hepatology, vol. 60, no. 6, pp. 19571962, 2014.

[61] M. L. Samoylova, J. L. Dodge, F. Y. Yao, and J. P. Roberts, "Time to transplantation as a predictor of hepatocellular carcinoma recurrence after liver transplantation," Liver Transplantation, vol. 20, no. 8, pp. 937-944, 2014.

[62] J. P. Roberts, A. Venook, R. Kerlan, and F. Yao, "Hepatocellular carcinoma: ablate and wait versus rapid transplantation," Liver Transplantation, vol. 16, no. 8, pp. 925-929, 2010.

[63] L. Kulik and M. Abecassis, "Living donor liver transplantation for hepatocellular carcinoma," Gastroenterology, vol. 127, no. 5, pp. S277-S282, 2004.

[64] J. I. Moon, C. H. D. Kwon, J. W. Joh et al., "Safety of small-forsize grafts in adult-to-adult living donor liver transplantation using the right lobe," Liver Transplantation, vol. 16, no. 7, pp. 864-869, 2010.

[65] H. Yokoi, S. Isaji, K. Yamagiwa et al., "Donor outcome and liver regeneration after right-lobe graft donation," Transplant International, vol. 18, no. 8, pp. 915-922, 2005.

[66] N. Akamatsu, Y. Sugawara, R. Nagata et al., "Adult right living-donor liver transplantation with special reference to reconstruction of the middle hepatic vein," American Journal of Transplantation, vol. 14, no. 12, pp. 2777-2787, 2014.

[67] M. H. G. Langenberg, M. W. Nijkamp, J. M. L. Roodhart et al., "Liver surgery induces an immediate mobilization of progenitor cells in liver cancer patients: a potential role for G-CSF," Cancer Biology \& Therapy, vol. 9, no. 9, pp. 743-748, 2014.

[68] K. Man, S. T. Fan, C. M. Lo et al., "Graft injury in relation to graft size in right lobe live donor liver transplantation: a study of hepatic sinusoidal injury in correlation with portal hemodynamics and intragraft gene expression," Annals of Surgery, vol. 237, no. 2, pp. 256-264, 2003.

[69] Z. F. Yang, R. T. Poon, Y. Luo et al., "Up-regulation of vascular endothelial growth factor (VEGF) in small-for-size liver grafts enhances macrophage activities through VEGF receptor 2-dependent pathway," Journal of Immunology, vol. 173, no. 4, pp. 2507-2515, 2004.

[70] A. Perrakis, T. Förtsch, V. Schellerer, W. Hohenberger, and V. Müller, "Biliary tract complications after orthotopic liver transplantation: still the "Achilles heel"?," Transplantation Proceedings, vol. 42, no. 10, pp. 4154-4157, 2010.

[71] K. S. H. Chok, S. C. Chan, T. T. Cheung et al., "Bile duct anastomotic stricture after adult-to-adult right lobe living donor 
liver transplantation," Liver Transplantation, vol. 17, no. 1, pp. 47-52, 2011.

[72] C. Heidenhain, J. Pratschke, G. Puhl et al., "Incidence of and risk factors for ischemic-type biliary lesions following orthotopic liver transplantation," Transplant International, vol. 23, no. 1, pp. 14-22, 2010.

[73] S. A. Shah, D. R. Grant, I. D. McGilvray et al., "Biliary strictures in 130 consecutive right lobe living donor liver transplant recipients: results of a western center," American Journal of Transplantation, vol. 7, no. 1, pp. 161-167, 2007.

[74] C. L. Berg, B. W. Gillespie, R. M. Merion et al., "Improvement in survival associated with adult-to-adult living donor liver transplantation," Gastroenterology, vol. 133, no. 6, pp. 1806$1813,2007$.

[75] K. M. Olthoff, R. M. Merion, R. M. Ghobrial et al., "Outcomes of 385 adult-to-adult living donor liver transplant recipients: a report from the A2ALL Consortium," Annals of Surgery, vol. 242, no. 3, pp. 314-323, 2005.

[76] M. Takatsuki, S. Eguchi, Y. Kawashita, and T. Kanematsu, "Biliary complications in recipients of living-donor liver transplantation," Journal of Hepato-Biliary-Pancreatic Surgery, vol. 13, no. 6, pp. 497-501, 2006.

[77] S. T. Fan, C. M. Lo, C. L. Liu, W. K. Tso, and J. Wong, "Biliary reconstruction and complications of right lobe live donor liver transplantation," Annals of Surgery, vol. 236, no. 5, pp. 676683, 2002.

[78] M. Takatsuki, Y. C. Chiang, T. S. Lin et al., “Anatomical and technical aspects of hepatic artery reconstruction in living donor liver transplantation," Surgery, vol. 140, no. 5, pp. 824-828, 2006.

[79] Y. Sugawara, K. Sano, J. Kaneko et al., "Duct-to-duct biliary reconstruction for living donor liver transplantation: experience of 92 cases," Transplantation Proceedings, vol. 35, no. 8, pp. 2981-2982, 2003.

[80] T. Ikegami, Y. Hashikura, Y. Nakazawa et al., "Risk factors contributing to hepatic artery thrombosis following livingdonor liver transplantation," Journal of Hepato-BiliaryPancreatic Surgery, vol. 13, no. 2, pp. 105-109, 2006.

[81] A. Giacomoni, A. Lauterio, A. O. Slim et al., "Biliary complications after living donor adult liver transplantation," Transplant International, vol. 19, no. 6, pp. 466-473, 2006.

[82] G. Y. Ko, K. B. Sung, H. K. Yoon, and S. G. Lee, "Early posttransplantation portal vein stenosis following living donor liver transplantation: percutaneous transhepatic primary stent placement," Liver Transplantation, vol. 13, no. 4, pp. 530-536, 2007.

[83] C. L. Liu, C. M. Lo, S. C. Chan, and S. T. Fan, "Safety of ductto-duct biliary reconstruction in right-lobe live-donor liver transplantation without biliary drainage," Transplantation, vol. 77, no. 5, pp. 726-732, 2004.

[84] E. Dulundu, Y. Sugawara, K. Sano et al., "Duct-to-duct biliary reconstruction in adult living-donor liver transplantation," Transplantation, vol. 78, no. 4, pp. 574-579, 2004.

[85] S. Hwang, S. G. Lee, K. B. Sung et al., "Long-term incidence, risk factors, and management of biliary complications after adult living donor liver transplantation," Liver Transplantation, vol. 12, no. 5, pp. 831-838, 2006.

[86] H. Khalaf, "Vascular complications after deceased and living donor liver transplantation: a single-center experience," Transplantation Proceedings, vol. 42, no. 3, pp. 865-870, 2010.
[87] M. Berenguer, M. Prieto, F. San Juan et al., "Contribution of donor age to the recent decrease in patient survival among HCV-infected liver transplant recipients," Hepatology, vol. 36, no. 1, pp. 202-210, 2002.

[88] D. J. Mutimer, B. Gunson, J. Chen et al., "Impact of donor age and year of transplantation on graft and patient survival following liver transplantation for hepatitis C virus," Transplantation, vol. 81, no. 1, pp. 7-14, 2006.

[89] U. P. Neumann, T. Berg, M. Bahra et al., "Long-term outcome of liver transplants for chronic hepatitis C: a 10-year followup," Transplantation, vol. 77, no. 2, pp. 226-231, 2004.

[90] M. Prieto, M. Berenguer, J. M. Rayón et al., "High incidence of allograft cirrhosis in hepatitis $\mathrm{C}$ virus genotype $1 \mathrm{~b}$ infection following transplantation: relationship with rejection episodes," Hepatology, vol. 29, no. 1, pp. 250-256, 1999.

[91] P. A. Sheiner, M. E. Schwartz, E. Mor et al., "Severe or multiple rejection episodes are associated with early recurrence of hepatitis C after orthotopic liver transplantation," Hepatology, vol. 21, no. 1, pp. 30-34, 1995. 